\title{
LES VOCALS MITJANES DELS PARLANTS DE TWI EN LA PARLA ESPONTȦNIA DEL CATALÀ
}

\author{
Laura Carrasco \\ lcarrasc@xtec.cat \\ Neus Frigolé \\ neusfrigole@gmail.com \\ Xavier Planàs \\ xplanas5@gmail.com \\ Departament d'Educació de la Generalitat de Catalunya
}

\begin{abstract}
Resum
A les societats actuals hi ha la convivència de diferents comunitats lingüístiques en un mateix marc social degut als fluixos migratoris. Thomason (2011) parla de contacte de llengües quan s'utilitza més d'un llenguatge en el mateix lloc al mateix moment. Aquest contacte pot generar situacions d'influència entre llengües que provoquen certes interferències entre elles. Per aquest motiu, hem volgut explorar si s'observen fenòmens de transferència fonètica en les vocals mitjanes dels parlants de Twi en la parla espontània del català. En aquest estudi s'han descrit acústicament les vocals mitjanes i s'han comparat els resultats obtinguts amb l'estudi de Rius-Escudé (2015) en què es descriuen les vocals del català central en parla espontània. L'anàlisi de les vocals s'ha realitzat mitjançant el programa d'anàlisi fonètic Praat. El corpus de parla espontània utilitzat està compost per 144 enunciats obtinguts a partir d'una interacció professor-alumne. Els resultats demostren que entre les vocals mitjanes dels parlants de Twi en parla espontània del català i les vocals del català central analitzades per Rius-Escudé no hi ha diferències significatives i per tant, no podem parlar de transferència fonètica. Les diferències més notòries es troben en la producció de la $[\varepsilon]$ i la $[\mathrm{e}]$.
\end{abstract}

Paraules clau: parla espontània, vocals mitjanes, parlants Twi.

\section{Resumen}

En las sociedades actuales conviven diferentes comunidades lingüísticas en un mismo marco social, debido a los flujos migratorios. Thomason (2011) habla de contacto de lenguas cuando se usa más de una en el mismo lugar y en el mismo momento. Este contacto puede generar situaciones de influencia entre lenguas que provocan ciertas interferencias entre ellas. Por este motivo, hemos querido explorar si se observan fenómenos de transfrencia fonética en las vocales medias de los hablantes de Twi en el habla espontánea del catalán. En este estudio se han descrito acústicamente las vocales medias y se han comparado los resultados obtenidos con el estudio de Rius-Escudé (2015) en el que se describen las vocales del catalán central en habla espontánea. En análisis de las vocales se ha realizado mediante el programa de análisis fonético Praat. El corpus de 
habla espontánea utilizado está compuesto por 144 enunciados obtenidos a partir de una interacción profesor-alumno. Los resultados demuestran que entre las vocales medias de los hablantes de Twi en habla espontánea del catalán y las vocales del catalán central analizadas por Rius-Escudé no hay diferencias significatives $\mathrm{y}$, por tanto, no podemos hablar de transferencia fonética. Las diferencias más notorias se encuentran en la producción de la $[\varepsilon]$ y la $[\mathrm{e}]$.

Palabras clave: habla espontánea, vocales meidas, hablantes Twi.

\begin{abstract}
In current societies there is the coexistence of different linguistic communities in the same social context due to a flow of migrants. Thomason (2011) talks about language contact when more than one language is spoken in the same place at the same moment. This contact can influence these languages creating certain interference between them. For this reason, we wanted to explore if there is phonetic transfer phenomena in mid vowels produced by Twi speakers in spontaneous speech in Catalan. In this study we have described mid vowels acoustically and we have compared our results with the ones obtained by Rius-Escudé (2015) in which central Catalan vowels in spontaneous speech were described. We have used the programme of phonetic analysis Praat to carry out the analysis of vowels. Our corpus is composed of 144 statements obtained through an interaction teacher-student. Results show that there are no significant differences between the mid vowels produced by Twi speakers in spontaneous speech in Catalan and the vowels of central Catalan analized by Rius-Escudé (2015). Therefore, we cannot talk about phonetic transfer. The most relevant differences are found in the production of $[\varepsilon]$ and $[\mathrm{e}]$.
\end{abstract}

Key words: spontaneous speech, mid vowels, Twi speakers

\title{
1. INTRODUCCIÓ
}

La realitat social catalana ha canviat molt en els darrers anys ja que els fenòmens de globalització han permès un augment en la mobilitat de la població mundial. El flux migratori ha generat un augment considerable de la població catalana ja que en els últims 20 anys hi ha hagut un increment de 1.300 .000 persones.

Aquest fet ha suposat un canvi en la demografia. En gran part es pot atribuir el creixement poblacional a l'arribada de persones que han nascut a fora del territori català. Això suposa un nou paradigma social on es posa en joc un marc de convivència amb moltes comunitats de diferents cultures i nacionalitats amb llengües pròpies.

En el camp educatiu aquesta nova realitat ha suposat un canvi generalitzat en la composició de l'alumnat de les escoles i per tant una necessitat d'adaptació a aquest nou context. Així Serra et al (2008) van observar com hi havia certes adaptacions del sistema 
educatiu català per tal de donar acollida a aquests infants que arribaven en edat d'escolarització sense la llengua vehicular escolar. Un recurs que es va proposar va ser la creació d'una estructura educativa que permetés fer un aprenentatge intensiu de la llengua catalana anomenant-la aules d'acollida.

La implementació d'aquest servei va establir una mesura extraordinària per tal de donar resposta a una realitat canviant. Actualment, però, ens adonem que l'evolució del fenomen migratori es situa en un segon estadi. Les famílies estan més arrelades al territori i els fills, nascuts a Catalunya, ja comencen l'escolarització al sistema educatiu català als primers nivells escolars.

Per tant, ens cal replantejar canvis estructurals i metodològics que recondueixin la promoció dels alumnes davant aquest nou context. Hi ha l'evidència que el fracàs escolar incideix directament en les condicions de vida de l'edat adulta i que, per tant, afecta directament la cohesió social (Collet, 2012). És important destacar que gran part de les situacions de risc que s'observen tenen la seva arrel a l'educació primària. A partir de la cimera de Lisboa del $2000 \mathrm{~s}$ 'han posat en marxa diverses actuacions per reduir aquestes quotes de fracàs escolar (Collet, 2012).

Un dels punts que es destaquen en el moment d'analitzar les taxes de fracàs escolar, a partir de les proves d'avaluació Progress in International Reading Literacy Study (PIRLS) i Programme for International Student Assessment (PISA), és la baixa puntuació dels alumnes d'origen immigrat en les proves de competència lingüística (Bonet, 2012). Aquest factor ens fa situar el focus d'atenció en el desenvolupament d'aquestes capacitats, en clau multicultural i plurilingüe.

Per aquest motiu, ens cal explorar específicament si l'aprenentatge de la llengua catalana en aquests entorns plurilingües rep influències de les llengües maternes que modifiquen o afecten el desenvolupament de les capacitats orals en llengua catalana. Així doncs, el nostre objectiu general de recerca ha estat explorar si la producció dels sons de les vocals anteriors i posteriors, en concret dels sons $[\varepsilon],[\mathrm{e}],[0] \mathrm{i}[\mathrm{o}]$, dels nens catalanoparlants d'origen ghanès es veu influenciada per la seva llengua materna, el Twi. Aquest fet ens permetria explorar si un dels factors que incideixen en l'aprenentatge de la competència lingüística és la influència de la llengua materna.

Després de veure que no hi ha estudis que analitzen la parla espontània del català produïdes per informants de parla Twi, ens hem proposat una sèrie d'objectius:

1. Descriure acústicament les vocals mitjanes en parla espontània en llengua catalana produïdes per informants que tenen el Twi com a llengua materna.

2. Comparar i valorar els resultats obtinguts amb l'estudi de Rius-Escudé (2015) en què es descriuen les vocals del català central en parla espontània. Observant els fenòmens de transferència fonètica observats entre el Twi i la llengua catalana.

Aquest estudi s'emmarca dins de l'anàlisi de parla espontània. Pensem que per tal de poder portar a terme un anàlisi adequat és necessari basar-nos en l'espontaneïtat de la parla ja que d'aquesta manera evitem que el discurs hagi estat preparat $\mathrm{i}$ ens assegurem que sigui el més natural i real possible 


\section{CONTEXTUALITZACIÓ}

L'escola la Sínia està situada al barri del Remei de Vic. Un barri que ha sigut d'acollida dels diferents corrents migratoris generats des de mitjans del s. XX, de procedència majoritàriament intraestatal, fins als corrents migratoris d'inici del segle XXI, caracteritzats pels fenòmens de globalització, de procedència africana, asiàtica i sudamericana majoritàriament. Actualment, segons dades del cens de la població de Vic del 2013, hi ha un 33\% de la població del barri d'origen immigrant amb puntes de concentració en blocs d'habitatges de fins el $60 \%$.

Això vol dir que es mostra com un barri amb arrels multiculturals marcades on la convivència de les diferents comunitats es contempla com una oportunitat de la coneixença mútua des del respecte i el civisme. La nostra escola acull un total de 21 nacionalitats acompanyades, moltes vegades, de múltiples representacions lingüístiques i culturals.

En aquest entorn plurilingüe s'observa la llengua catalana com a frontissa intercultural i com a vehicle de comunicació i interacció entre la comunitat educativa. Per tant l'objectiu principal del nostre treball és dotar d'eines a l'alumne per tal que es pugui desenvolupar tant en l'aspecte social, personal $i$ acadèmic per poder participar activament com a ciutadà de ple dret primer en la comunitat escolar i posteriorment en el teixit social de la ciutat. Per aquest motiu, es vetlla per tenir controlades les interaccions específiques que es produeixen en l'entorn de l'alumne (familiar, social i escolar) a través de la coordinació intensiva dels serveis d'assistència primària amb l'objectiu de fomentar l'estímul pels aprenentatges i garantir un creixement global equilibrat.

Una de les comunitats amb més representació al centre és la comunitat ghanesa on suposa vora del $20 \%$ de l'alumnat. Aquesta comunitat mostra un arrelament en el teixit social havent-se organitzat com a associació ja des del 2002. Compta amb una seu pròpia on desenvolupen activitats socioculturals que promouen una progressiva vinculació amb les associacions de Vic. La presència de població ghanesa a Osona ja es mostra consolidada fent que molts dels infants que pertanyen a famílies d'origen ghanès siguin nascuts a Vic $\mathrm{o}$ en territori català.

Ghana (veure figura 1) s'observa com un país divers amb diferents ètnies amb característiques singulars distribuïdes al llarg 10 regions diferents. D'entre aquests grups podem destacar les següents comunitats: Akan, Ewe, Guan, Ga-Adange i els de la regió del Togo central. La diversitat lingüística també és notòria ja que es parlen més de 50 llengües distribuïdes desigualment ja que la distribució de la població arreu del territori observa petits grups ètnics amb llengua pròpia en regions de difícil accessibilitat. Podem observar dos grans grups d'aquestes llengües que s'estenen al llarg de diferents regions africanes com són la Kwa, parlada al sud del país i les llengües d'origen Gur. Cal destacar com a llengua cooficial la anglesa, vestigi de la colonització anglesa fins el 6 de març de 1957 moment en el que s'independitza.

La majoria dels nostres alumnes procedeixen de les regions del sud de Ghana pertanyent a la comunitat dels Akan on es parlen principalment 3 dialectes akanics: l'Aixanti, el Twi i 
el Fanti. Aquestes estan regulades i unificades des de1978 per un comitè ortogràfic de l'Akan

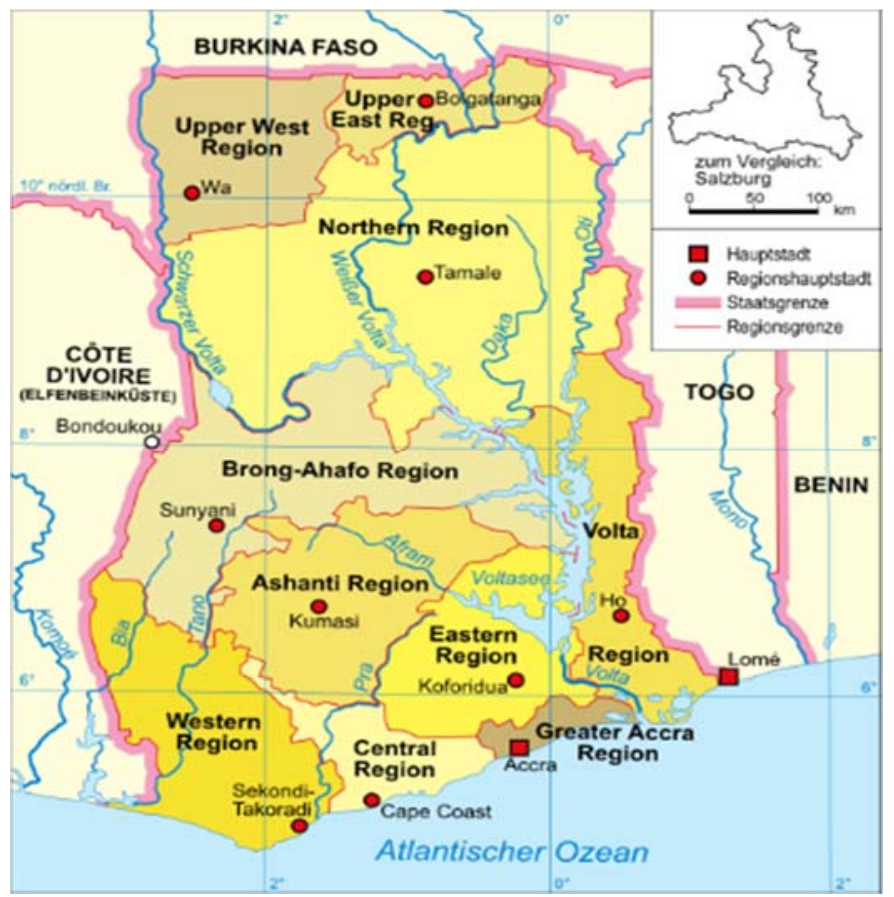

Figura 1. Mapa de Ghana

\section{MARC TEÒRIC}

Un fenomen que es produeix a les societats actuals és la convivència de diferents comunitats lingüístiques en un mateix marc social degut als fluixos migratoris globalitzats. Aquest fet fa que es generin situacions de contacte entre llengües generant situacions de multilingüismes en diferents contextos públics i situacions de plurilingüisme en els individus que en formen part. Així doncs, podem agafar com a nostra la definició que ens ofereix Thomason (2011) que parla de contacte de llenguatges quan s'utilitza més d'un llenguatge en el mateix lloc al mateix moment.

Thomason (2001) ha observat com aquest contacte pot generar situacions d'influència entre llengües que provoquin certes interferències entre elles. Observant en especial atenció la influència en els processos d'adquisició de segones llengües.

Si posem el focus en aquests processos d'aprenentatge de segones llengües ens adonem que la influència de la llengua materna s'evidencia en la utilització d'estratègies d'aproximació fonètica en base al sistema fonètic conegut de la L1 (Best, 1995; Best i Tyler, 2007). Per tant, per accedir a la L2 agafa pes la base fonètica de la llengua materna observant així l'aprenentatge a partir d'estratègies interlingüístiques que acaben generant un espai fonològic compartit.

En aquest sentit Thomason (2011) obre una porta interessant al observar que existeix una desigualtat entre les llengües en aquests fenòmens de contacte lingüístic. Així, es pot observar com en un mateix territori l'ús social de certes llengües pot presentar certa jerarquització. Aquest fet suposa evidenciar que la influència de determinats idiomes 
tingui més pes d'acord a la posició social que ocupa en el seu territori. Serà doncs a partir d'observar aquestes relacions d'influència jerarquitzada que es podrà observar els efectes d'aquesta relació entre llengües.

Aquests efectes són múltiples i afecten els diferents àmbits del llenguatge com poden ser la fonètica, la sintaxi, la morfologia i també la semàntica. Entre aquests fenòmens es poden observar: fenòmens de transferència; fenòmens d'interferències gramaticals; fenòmens d'apropiació lèxica; canvis de codis lingüístics en un mateix discurs o barreges de codis en un mateix discurs (Davies, 1990). En el nostre cas, estem interessats en observar els fenòmens de transferència fonètica que es poden produir en parlants bilingües de Twi i català.

Per tal de realitzar aquest estudi comparatiu cal observar que, a la literatura científica es poden trobar estudis i assajos que defineixen fonèticament el Twi i les seves principals característiques. Es tracta d'una llengua amb una gran varietat de vocals (fins a 14 fonemes diferenciats) que a més presenten fenòmens d'harmonització vocàlica. Una altra característica important a considerar es que es tracta d'un llenguatge que utilitza tres tons fonètics.

En el camp de la fonètica comparada, però, no hi ha gaire recorregut pel que fa a altres estudis que hagin observat el contacte del Twi amb altres llengües. Sols trobem un estudi comparatiu dels fenòmens de contacte fonològic entre el Twi i l'anglès a Ghana. En l'àmbit català no s'observa cap estudi que posi en joc aquestes dues llengües per la qual cosa no es podran observar precedents que puguin ajudar a donar major validesa als nostres resultats.

Hi ha diversos autors que han estudiat la fonètica del català. Ens centrarem, però, en dos dels autors que han estudiat el vocalisme del català fins el moment.

\subsection{Estudis de les darreres dècades del S. XX. Daniel Recasens.}

Recasens (1986) va constatar que les vocals àtones tendeixen a trobar-se, en el camp de dispersió, més centralitzades que les vocals tòniques. Aquí ens interessarem per les dues vocals que estudiarem al llarg de l'article [e] i [o].

Pel que fa al fonema mitjà anterior no labialitzat /e/, quan el trobem en contacte amb una /i/, amb una consonant palatal o una consonant velar, hi ha una elevació lingual de la /e/ i un descens acústic d'F $F_{1}$ i F2. Quan ens trobem una consonant nasal implosiva davant d'una altra consonant també es pot apreciar un ascens de la /e/ que la precedeix (Recasens, 1986).

Quant al fonema mitjà baix anterior no labialitzat $/ \varepsilon /$, Recasens (1993:81) remarca la tendència a l'obertura i posteriorització de la / $/$ / en contacte amb la [1] velaritzada, vibrant i bategant. En relació amb les dades acústiques del català central hi ha un descens de l' $\mathrm{F}_{2}$ de la $/ \varepsilon /$ en contextos simètrics amb aquestes consonants (Recasens, 1986). En contacte amb consonants labials, [w], [u] i vocals labialitzades presenten el mateix efecte acústic. Per altra banda, en contacte amb vocals altes anteriors i amb consonants palatals i velar anteriors, la realització de la / $/ \varepsilon /$ és més alta (hi ha un descens $d^{\prime} F_{1}$ ) i anterior (hi ha un ascens $\mathrm{d}^{\prime} \mathrm{F}_{2}$ ). 
Segons Recasens (1993), la configuració lingual del fonema mitjà alt posterior labialitzat /o/ no es veu afectada per les articulacions posteriors adjacents. Les vocals més obertes i les consonants ([1], [r] i [a]) fan que hi hagi un increment del grau d'obertura oral de la /o/. Per altra banda, les consonants i vocals més labialitzades $([\mathrm{w}] \mathrm{i}[\mathrm{u}])$ afavoreixen un increment del grau de tancament oral i de labialització de la /o/.

Les consonats palatals i dentoalveolars, i les vocals anteriors promouen un increment dels graus d'avançament lingual i deslabialització de la / $/ 2$ adjacent. Com a conseqüència hi ha un augment de l'F $F_{2}$ vocàlic.

\subsection{Estudis d'inicis del segle XXI. Agnès Rius-Escudé}

Seguint Rius-Escudé (2015), des d'un punt de vista acústic, hi ha més diferència entre les dues vocals mitjanes anteriors ([e] i $[\varepsilon])$ que entre les dues posteriors ([o] i [o]). Per altra banda, també constata que hi ha diferències significatives entre homes i dones en la producció d'aquestes vocals. Segons l'autora, les dones presenten valors acústics més elevats en tots els casos degut a diferències anatòmiques de les cordes vocals i de la cavitat bucal d'uns i altres.

Rius-Escudé també indica que el punt d'articulació dels sons adjacents anteriors en les vocals mitjanes posteriors en parla espontània és rellevant, però en les vocals anteriors no gaire.

Cal destacar que Recasens ha portat a terme tots els seus estudis en homes i que es tracta de parla de laboratori. Rius-Escudé, en canvi, ha analitzat la producció de sons tant en homes com en dones i els seus anàlisis es centren en la parla espontània.

Rius-Escudé defensa que el fet que l'F $F_{1}$ de les vocals tingui un valor acústic més alt vol dir que en parla espontània aquestes son més obertes que en la parla de laboratori. L'F2 de les vocals posteriors, els valors també son més elevats en parla espontània (excepte en algun cas). Això significa que presenten menys constricció linguovelar i menys labialització. Pel que fa a les vocals anteriors, en canvi, els valors acústics son mitjans i, en algun cas, com ara el de la vocal mitjana anterior alta, [e], baix. Per Rius-Escudé, això implica que les vocals anteriors en parla espontània no tenen tant avançament lingual ni tanta constricció dorsopalatal. Els valors acústics dels dos primers formants de les vocals del català central en parla espontània són més centrals que els de parla de laboratori. Això vol dir que són més obertes. 


\section{CORPUS}

El nostre estudi es centra en informants catalanoparlants de la comunitat Akan que tenen com a llengua materna el Twi i viuen a la comarca d'Osona. Així doncs, ens basarem en la varietat del català central (veure figura 2).

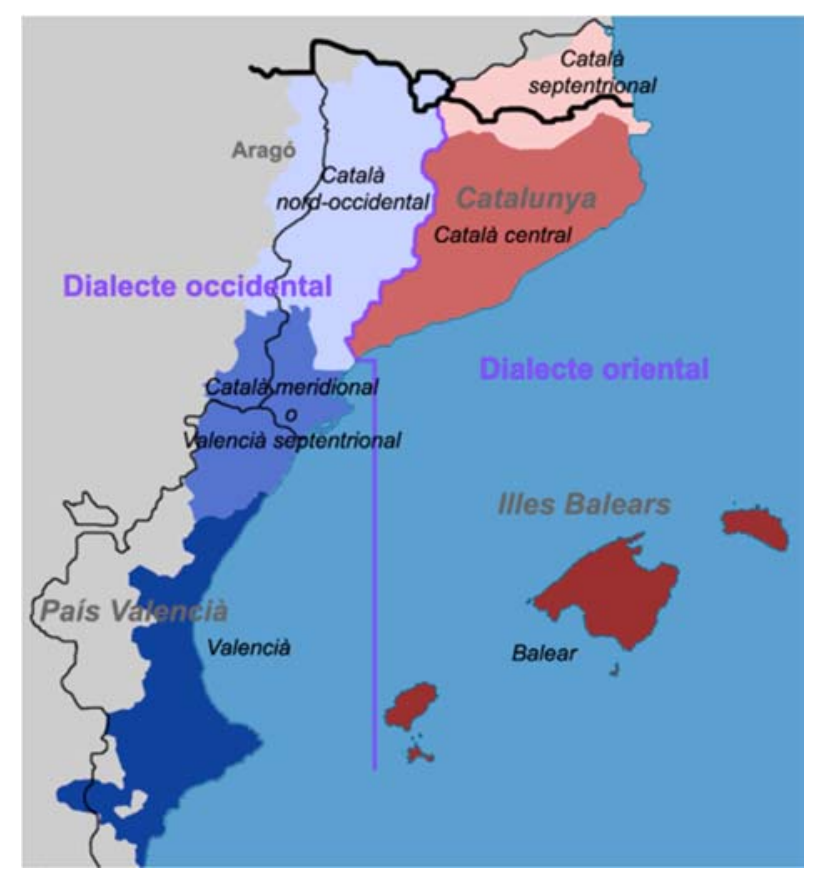

Figura 2.Ccatalà central

Els criteris de selecció de la mostra han contemplat que els nostres informants s'haguessin incorporat al sistema educatiu català ens els primers períodes d'educació infantil i així, assegurar-nos que hagin tingut contacte intensiu amb la llengua catalana durant un llarg període de temps. Aquest fet ens ha restringit la població mostral als alumnes de cicle superior d'educació primària on es contempla un mínim de contacte d'entre 8 i 9 anys. Per tal de controlar diferents biaixos també s'han tingut en compte les variables de rendiment acadèmic $\mathrm{i}$ de necessitats educatives especials per evitar que interfereixin dificultats d'aprenentatge a possibles trastorns d'aprenentatge o de salut.

Entre una mostra de 10 alumnes, s'han seleccionat 3 alumnes (dos nens i una nena) d'entre 10 i 11 anys que presenten unes característiques individuals que ens fa pensar que no hi ha possibles variables que esbiaixin els resultats. A continuació podem observar les seves característiques:

Alumne 1: L'alumne observa un entorn social estable on es desenvolupa amb normalitat. Les habilitats lingüístiques en les diferents llengües són adequades i es destaca un nivell notable en llengua anglesa. Nascut a territori català, la seva família parla amb fluïdesa la llengua catalana. Cal destacar la participació en clubs esportius i els lligams de la família en el seu entorn de relació. Presenta un bon nivell de benestar socioeconòmic. 
Alumne 2: S'observa un arrelament fort al territori observant-se participació en diferents entitats de la ciutat. El seu desenvolupament acadèmic ha estat creixent i presenta uns nivells d'assoliment lingüístics suficients, destacant un alt nivell en llengua anglesa. Conviu en un entorn familiar on entre germans parlen la llengua catalana de forma habitual, tot i que amb els pares parlen regularment el Twi. És nascuda a Vic i es va incorporar a l'escola a p3.

Alumne 3: Nascut a Vic i incorporat a l'escola a P3. El seu entorn familiar és referent per a la comunitat i aquest fet fa que s'observi un bon domini dels principals dialectes de l'Akan i altres llengües com el Hausa. Està alfabetitzat en diferents sistemes com l'àrab i observa nivells d'assoliment $\mathrm{i}$ competència adequats en català i castellà. També com els altres alumnes presenta un nivell alt en llengua anglesa, degut a la assistència a classes extraordinàries dins la comunitat ghanesa. El nivell de benestar socioeconòmic és bo.

El nostre corpus està format per 144 enunciats obtinguts a partir d'una interacció amb un dels professors de l'escola. El professor els va demanar que fessin una descripció d'un tema que ell els va proporcionar. Vam decidir analitzar les vocals mitjanes. El corpus que hem obtingut (vegeu taula 1 i gràfic 1 ) és de 20 vocals mitjanes baixes anteriors $[\varepsilon]$, un $14 \%$ del total; 56 vocals mitjanes altes anteriors [e], un 39\% del total; 36 vocals mitjanes baixes posteriors [0], un $25 \%$ del total i 32 vocals mitjanes altes posteriors [o], un $22 \%$ del total.

\begin{tabular}{|c|c|c|}
\hline So & Classificació & Nombre \\
\hline$[\varepsilon]$ & vocal mitjana baixa anterior & 20 \\
\hline$[\mathrm{e}]$ & vocal mitjana alta anterior & 56 \\
\hline$[0]$ & vocal mitjana baixa posterior & 36 \\
\hline$[\mathrm{o}]$ & vocal mitjana alta posterior & 32 \\
\hline \multicolumn{2}{|c|}{ Taula 1. Sons del corpus }
\end{tabular}

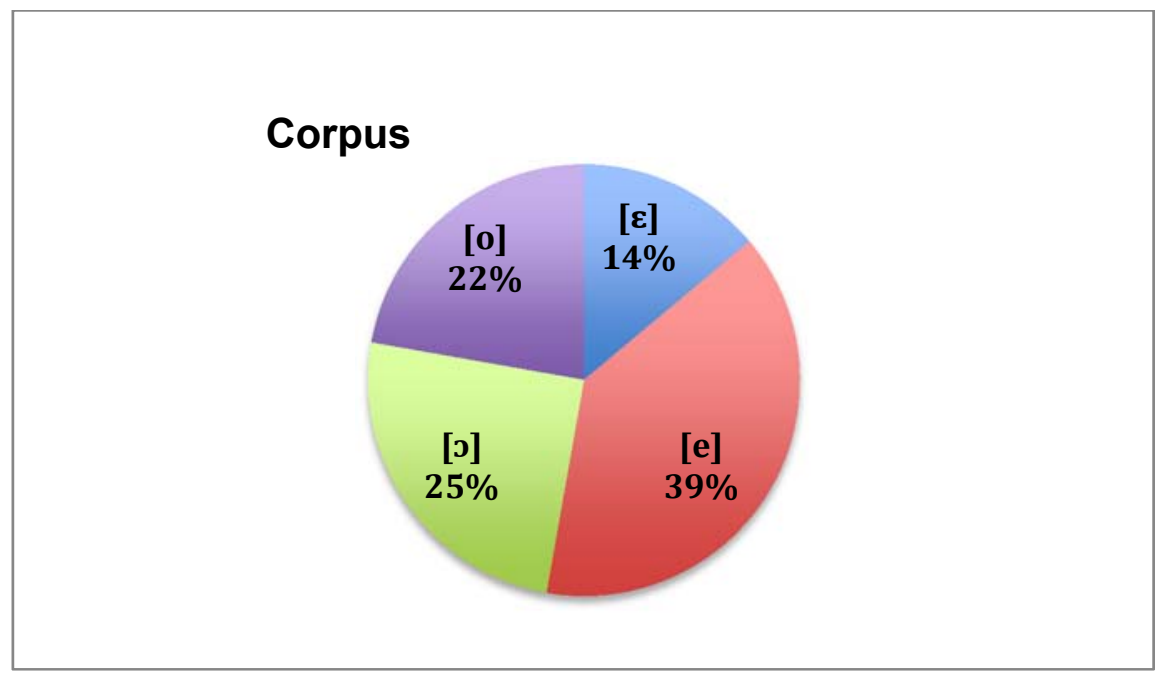

Gràfic 1. Percentatge de cada so vocàlic

Si ens fixem en la taula 1 i el gràfic 1 , podem observar que la vocal més representada en el nostre corpus és la [e] amb un 39\%. Tot i així, veiem que la mostra és bastant homogènia. 
Cal destacar també que els entre els nostres informants trobem dos nens i una nena. Pel que fa al sexe masculí hem analitzat un total de 94 sons (taula 2) i pel femení, un total de 50 (taula 3). El corpus que hem obtingut pel sexe masculí (vegeu taula 2) és de 13 vocals mitjanes baixes anteriors $[\varepsilon]$, un $14 \%$ del total; 41 vocals mitjanes altes anteriors [e], un $44 \%$ del total; 19 vocals mitjanes baixes posteriors [0], un $20 \%$ del total i 21 vocals mitjanes altes posteriors [o], un 22\% del total. Quant al sexe femení, el corpus obtingut (vegeu taula 3 ) és de 7 vocals mitjanes baixes anteriors $[\varepsilon]$, un 14\% del total; 15 vocals mitjanes altes anteriors [e], un 30\% del total; 17 vocals mitjanes baixes posteriors [0], un $34 \%$ del total i 11 vocals mitjanes altes posteriors [o], un $22 \%$ del total.

Com podem veure a la taula 2 i 3, s'han analitzat una quantitat de sons més elevada en el sexe masculí que en el sexe femení. Destaquem la diferència d'enunciats quant a la [e]. Per a aquest so, no podem considerar la nostra mostra homogènia, però pensem que pel que fa a la resta de sons, disposem d'una mostra comparable en ambdós sexes.

\begin{tabular}{|c|c|c|c|}
\hline So & Classificació & Nombre & Percentatge \\
\hline$[\varepsilon]$ & $\begin{array}{c}\text { vocal mitjana } \\
\text { baixa anterior }\end{array}$ & 13 & 13 \\
\hline$[\mathrm{e}]$ & $\begin{array}{c}\text { vocal mitjana } \\
\text { alta anterior }\end{array}$ & 41 & 41 \\
\hline$[0]$ & $\begin{array}{c}\text { vocal mitjana } \\
\text { baixa posterior }\end{array}$ & 19 & 19 \\
\hline$[\mathrm{o}]$ & $\begin{array}{c}\text { vocal mitjana } \\
\text { alta posterior }\end{array}$ & 21 & 21 \\
\hline
\end{tabular}

Taula 2. Sons corpus informants masculins

\begin{tabular}{|c|c|c|c|}
\hline So & Classificació & Nombre & Percentatge \\
\hline$[\varepsilon]$ & $\begin{array}{c}\text { vocal mitjana } \\
\text { baixa anterior }\end{array}$ & 7 & $14 \%$ \\
\hline$[\mathrm{e}]$ & $\begin{array}{c}\text { vocal mitjana } \\
\text { alta anterior }\end{array}$ & 15 & $30 \%$ \\
\hline$[\mathrm{o}]$ & $\begin{array}{c}\text { vocal mitjana } \\
\text { baixa posterior }\end{array}$ & 17 & $34 \%$ \\
\hline$[\mathrm{o}]$ & $\begin{array}{c}\text { vocal mitjana } \\
\text { alta posterior }\end{array}$ & 11 & $22 \%$ \\
\hline
\end{tabular}

Taula 3. Sons corpus informant femení

\section{METODOLOGIA}

Per dur a terme aquesta investigació hem demanat a tres nens (dos nens i una nena) de l'escola de la Sínia (Vic) que fessin la descripció d'un tema escollit a l'atzar per un dels investigadors, el qual és professor d'aquesta escola. Tot i ser ell el que estava present a l'hora de fer les gravacions, no ha interferit en cap moment. S'ha limitat a escoltar els nens $i$ si en algun moment es quedaven sense idees, els ha ajudat per tal que la seva contribució fos més extensa i ens permetés tenir una gravació més llarga i així poder analitzar més sons. 
Els altres dos investigadors han estat els que han fet la selecció dels enunciats i només han tingut en compte que el soroll de fons o la veu de l'entrevistador no s'encavalquessin amb la veu dels informants. Així doncs, la tria de les vocals mitjanes ha estat seleccionada a partir d'aquests enunciats.

Una vegada hem tingut els enunciats separats hem quantificat les dades per tal de poder calcular els percentatges. Els enunciats han estat classificats en vocal mitjana baixa anterior $[\varepsilon]$, vocal mitjana alta anterior [e], vocal mitjana baixa posterior [0] i vocal mitjana alta posterior [o]. També han estat quantificats tenint en compte el sexe de l'informant.

El corpus de la nostra investigació té una duració total de 10 minuts i 18 segons. Tots els nostres informants són nens d'entre 10 i 11 anys els quals la seva llengua materna és el Twi. Després d'escoltar tots els àudios, hem fer una primera selecció i hem exclòs les parts de la gravació on l'àudio no era suficientment clar per tal d'analitzar els sons. En una segona selecció, hem escollit tots els sons susceptibles de ser analitzats i hem anotat en una fitxa de dades cada so (nom de l'informant, número informant, número d'àudio $\mathrm{i}$ paraula o frase on s'ha produit).

A continuació hem guardat els àudios en format wav per tal de poder ser analitzats amb el programa PRAAT (Boersma i Weenink, 1992-2012). Hem seleccionat i hem tallat cada paraula que contenia la vocal que preteníem analitzar, li hem assignat un codi i l'hem desat en format wav per tal de poder ser analitzat acústicament després.

Hem analitzat cada arxiu amb el programa $P R A A T$ i n'hem extret els valors $\mathrm{F}_{1}$ i $\mathrm{F}_{2}$ (vegeu figura 3).

A continuació podem veure l'arxiu de veu Moha_inf_3_9_aquell dia.wav. El so analitzat en aquest cas ha estat la vocal mitjana baixa anterior $[\varepsilon]$ de la paraula aquell. Les línies vermelles de la imatge representen els formants de la vocal: l'F $F_{1}$ és el que es troba a la base i l'F $F_{2}$ és el que es representa just per sobre.

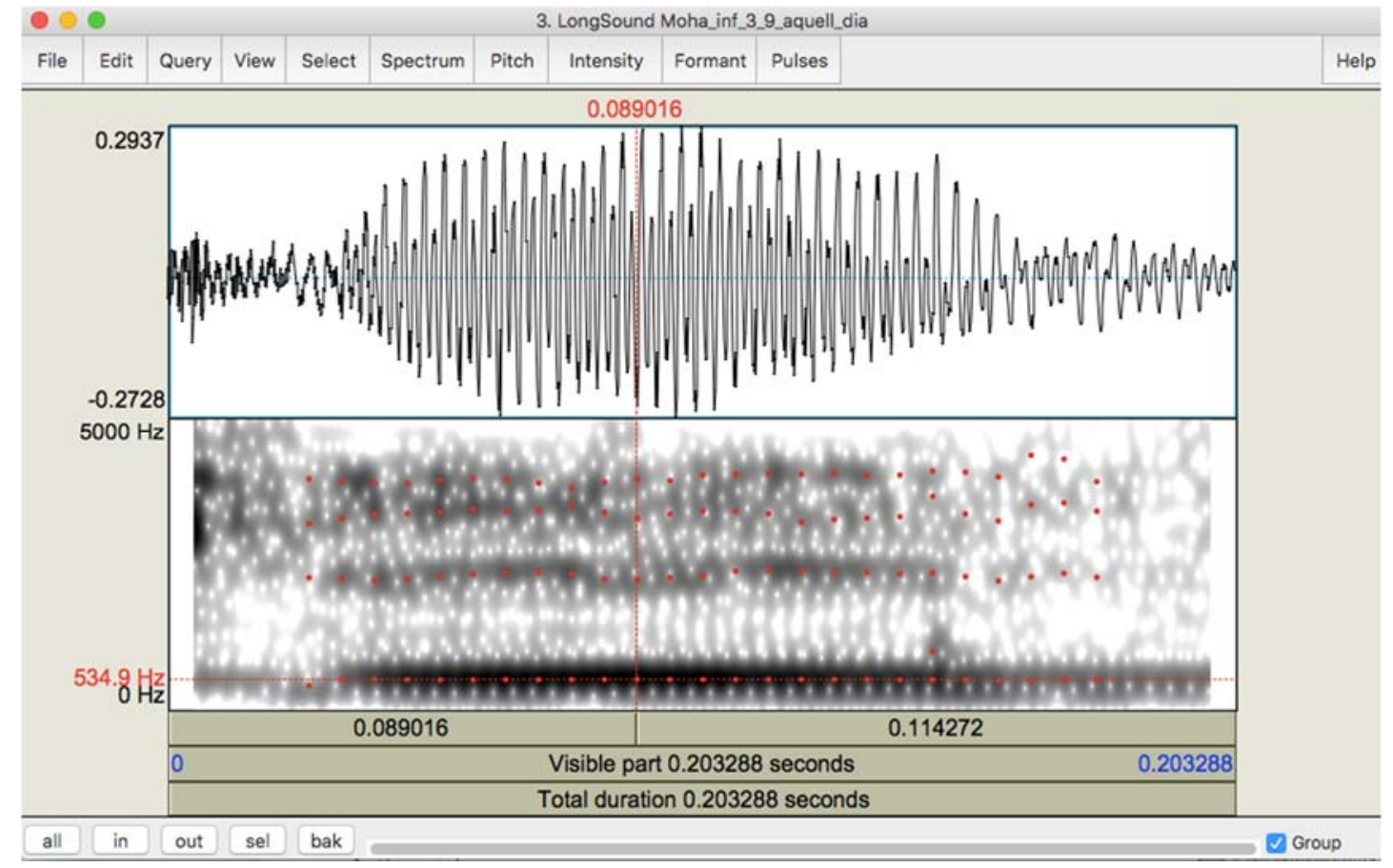

PHONICA, vol. 15, p. 23-49, 2019

ISSN:1699-8774 
Figura 3. Representació sonograma [ع] d'aquell de la frase, d'aquell dia.

Un cop analitzats els $\mathrm{F}_{1}$ i $\mathrm{F}_{2}$ de cadascun dels sons, els hem anotat en un full de dades. Hem creat tres fulls de dades, un per a cada un dels informants, els quals contenien 4 fulls diferents, un per a cada una de les vocals a analitzar. Un cop hem tingut tots els sons separats per informant (informant 1, 2 i 3 ) i per so a analitzar ([ع], e], [o] i [o]), hem sumat tots els valors de $\mathrm{F}_{1}$ i seguidament tots els $\mathrm{F}_{2}$ de cada un dels informants. Hem obtingut el percentatge de cadascun dels sons i de cadascun dels formants de la vocal $\left(\mathrm{F}_{1}\right.$ i $\left.\mathrm{F}_{2}\right)$. Un cop hem disposat dels percentatges de cada un dels informants, s'ha fet la mitjana de l' $F_{1}$ i després de l'F $F_{2}$ de cada un dels sons dels informants. Finalment, hem procedit a fer l'anàlisi de les vocals $([\varepsilon], \mathrm{e}],[0][\mathrm{o}])$ tenint en compte si l'informant era masculí o femení.

\section{ELS RESULTATS}

En aquest apartat descriurem els resultats obtinguts de la vocal mitjana baixa anterior $[\varepsilon]$, vocal mitjana alta anterior [e], vocal mitjana baixa posterior [0] i vocal mitjana alta posterior $[\mathrm{o}]$ en parla espontània dels parlants nadius de Twi quan parlen català. $\mathrm{A}$ continuació veurem les semblances $i$ les diferències que hi ha entre els sons vocàlics anteriors $/ \varepsilon, \mathrm{e} / \mathrm{i}$ els sons vocàlics posteriors $/ 0, \mathrm{o} /$ analitzats. Finalment, farem una comparació amb el vocalisme del català central en parla espontània dels sons vocàlics anteriorment anomenats basant-nos en Rius-Escudé (2015).

\subsection{Vocal mitjana anterior baixa $[\varepsilon]$}

Seguint l'esquema de les vocals cardinals de l'AFI (Jones, 1917), la vocal mitjana anterior baixa ocupa la part mitjana del costat esquerre en el triangle vocàlic (veure figura 4).

\section{Anterior $\quad$ Central $\quad$ Posterior}

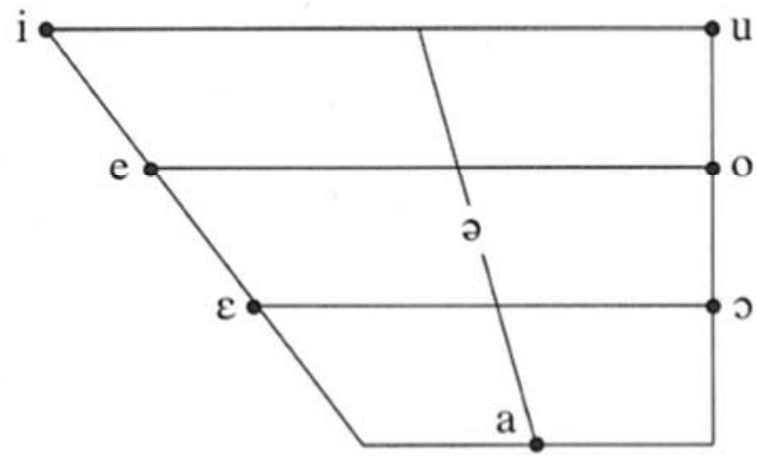

Figura 4. Representació vocàlica en el triangle vocàlic

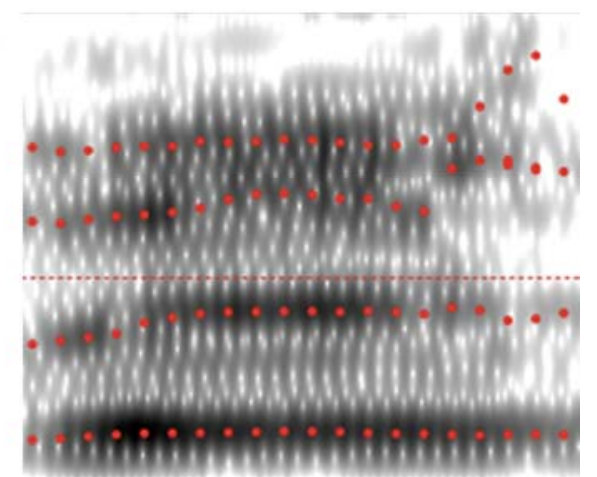

Figura 5. Sonograma de la vocal mitjana anterior baixa de saber

Com podem veure l' $F_{1}$ i l' $F_{2}$ de la $[\varepsilon]$ estan bastant separats. Entre altres paraules que presenten aquest so trobem perquè, veu, renya, què, negres, tiet, saber, aquell.

Per fer l'anàlisi ens hem basat en un total de 20 vocals mitjanes anteriors baixes. Això representa el 14\% del total del corpus analitzat. Un 35\% han estat produïdes per nenes i un $65 \%$ per nens (veure gràfic 2). 


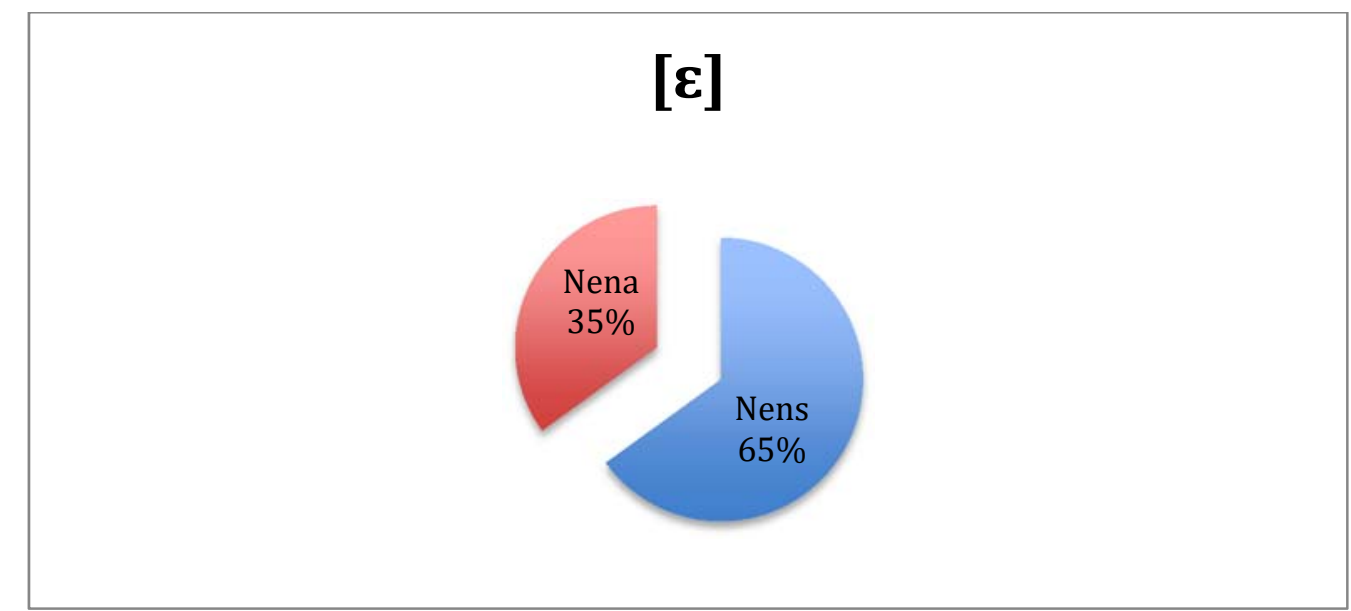

Gràfic 2 Percentatge de la vocal mitjana anterior baixa produïda per nens i nenes.

Les mitjanes dels valors acústics dels dos primers formants del so vocàlic $[\varepsilon]$ són les que podem veure a continuació:

\begin{tabular}{|l|c|c|}
\hline \multicolumn{1}{|c|}{ Informants } & {$[\boldsymbol{\varepsilon}]$} & {$[\boldsymbol{\varepsilon}]$} \\
\hline & $\mathbf{F}_{1}$ & $\mathbf{F}_{\mathbf{2}}$ \\
\hline 2 nens & 552,53 & 1972,97 \\
\hline 1 nena & 645,26 & 1904,81 \\
\hline
\end{tabular}

Taula 4. Dades acústiques d'F1 i F2 de la vocal [E] del català produïda per nens nadius de la llengua Twi

\begin{tabular}{|c|c|c|c|}
\hline Informants & Corpus & {$[\varepsilon]$} & {$[\varepsilon]$} \\
\hline & & $\mathbf{F}_{\mathbf{1}}$ & $\mathbf{F}_{\mathbf{2}}$ \\
\hline 69 homes & $\mathrm{PE} \mid$ & 556 & 1752 \\
\hline 62 dones & $\mathrm{PE}$ & 632 & 1969 \\
\hline
\end{tabular}

Taula 5. Resultats de les dades acústiques de l'F1 i F2 de la vocal [E] del català central obtinguts per Rius-Escudé (2015)

Si comparem els nostres resultats amb els resultats obtinguts per Rius-Escudé (2015) en què va analitzar les vocals del català central (vegeu taula 5) veiem que la diferència entre uns informants $\mathrm{i}$ els altres no és significativa quant a la producció de la vocal mitjana anterior baixa 
Pel que fa al nostre estudi, en l' $F_{1}$ hem obtingut en els nens un 552,5 i un 645,26 en la nena, amb una diferència del $16,8 \%$. Si ho comparem amb els resultats analitzats per Rius-Escudé (2015) els homes el valor dels homes va ser de 556 i el de les dones 632, amb una diferència del 16\%.

Si ens fixem en els resultats de l' $F_{1}$ dels informants masculins dels dos estudis, també trobem diferències. En el nostre estudi és 552,5 i el de Rius-Escudé (2015) 556 amb una diferència del $0,7 \%$. Pel que fa als informants femenins, el resultat de $l^{\prime} F_{1}$ del nostre estudi és 645,26 i el de Rius-Escudé (2015) és 632, amb una diferència del 2\%.

Els resultats de l' $F_{2}$ del nostre estudi tenim un valor de 1972,97 en els nens i 1904 en la nena, aquests resultats són una diferència del 3,4\%. I en l'estudi de Rius-Escudé (2015), els homes han obtingut 1752 i les dones 1969, amb una diferència del 12,4\%.

Si comparem l'F2 dels informants masculins del nostre estudi amb els de Rius-Escudé (2015), veiem que el resultat de l' $F_{2}$ dels informants masculins dels nostre estudi és 1972,97 i el de Rius-Escudé (2015) 1752, amb una diferència d'11,2\%. Pel que fa als informants femenins, el resultat de l'F $F_{2}$ del nostre estudi és 1904,81 i el de Rius-Escudé (2015) és 1969, amb una diferència del 3,4\%.

Així doncs, la diferència més rellevant la trobem en el segon formant $\left(\mathrm{F}_{2}\right)$ de la vocal $[\varepsilon]$ produïda pels nens. Pel que fa al sexe femení, la diferència és molt petita.

Per tal de representar el valor acústic mitja de $l^{\prime} F_{1}$ i de l' $F_{2}$ de la vocal mitjana anterior baixa del català produïda per nens nadius de Twi de la forma més representativa possible, hem optat per un gràfic de dispersió ja que d'aquesta manera podem apreciar les realitzacions d'aquest so vocàlic de forma més acurada. Els valors de l'F $F_{1}$ es troben a l'eix d'ordenades i els valors de l'F 2 a l'eix de les abscisses. A continuació podem veure dos gràfics de dispersió, un amb el camp de dispersió de la vocal mitjana anterior baixa produïda pel sexe masculí i un amb el camp de dispersió de la vocal mitjana anterior baixa produïda pel sexe femení.

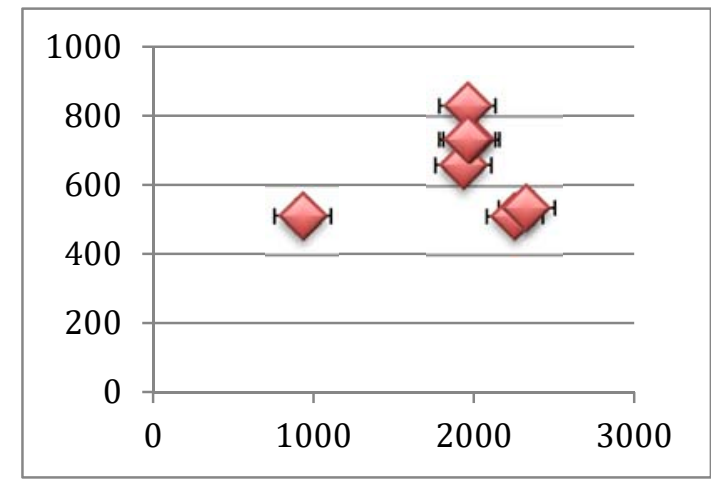

Gràfic 3. Camp de dispersió de la vocal [ع] del català produïda per l'informant femeni en parla espontània.

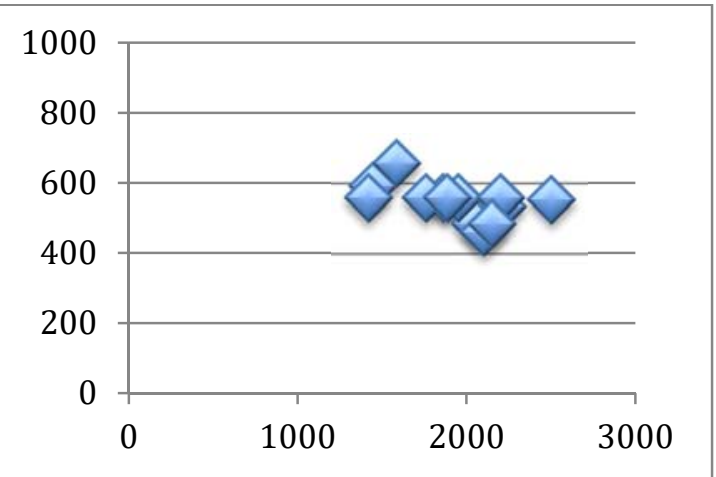

Gràfic 4. Camp de dispersió de la vocal [ع] del català produïda pels informants masculins en parla espontània.

Si comparem els dos gràfics, podem veure que el camp de dispersió de la vocal mitjana anterior baixa és molt més ampli en els nens que en la nena quant a l' $F_{2}$, però molt més ampli quant a l'F 1 en les nenes. En les nenes veiem que alguns valors passen dels 800 
mentre que en els nens no arriben als 800. Així doncs, podem veure que algunes realitzacions es concentren a la part més superior dreta, espai que correspon a la vocal mitjana alta anterior [e].

\subsection{Vocal mitjana anterior alta $[e]$}

Seguint l'esquema de les vocals cardinals de l'AFI (Jones, 1917), la vocal mitjana anterior alta ocupa la part esquerre en el triangle vocàlic, en una posició superior a la $[\varepsilon]$ (veure figura 4).

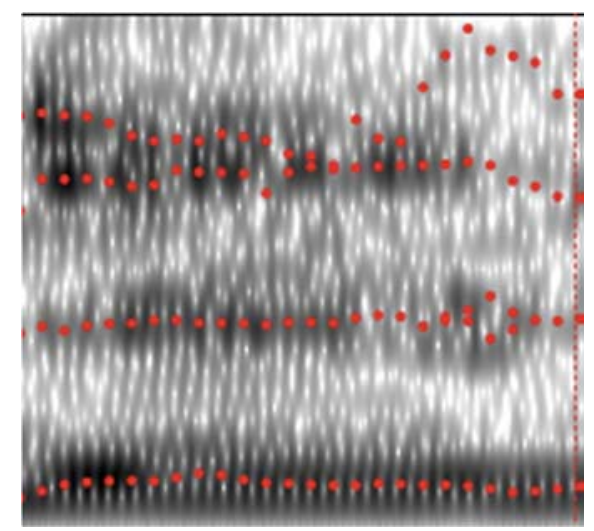

Figura 6. Sonograma de la vocal mitjana anterior alta de continent

Com podem veure l' $\mathrm{F}_{1}$ i l' $\mathrm{F}_{2}$ de la [e] estan més separats que el primer i el segon formant de la $[\varepsilon]$. De fet, una característica de la [e] és que presenta un F1 baix i un F2 alt. Així doncs, els dos formants es troben força separats entre ells. Entre altres paraules que presenten aquest so trobem meva, després, sempre, ser, seu, bomber.

Per fer l'anàlisi ens hem basat en un total de 56 vocals mitjanes anteriors altes. Això representa el 39\% del total del corpus analitzat. Un 35\% han estat produïdes per nenes i un $65 \%$ per nens (veure gràfic 5).

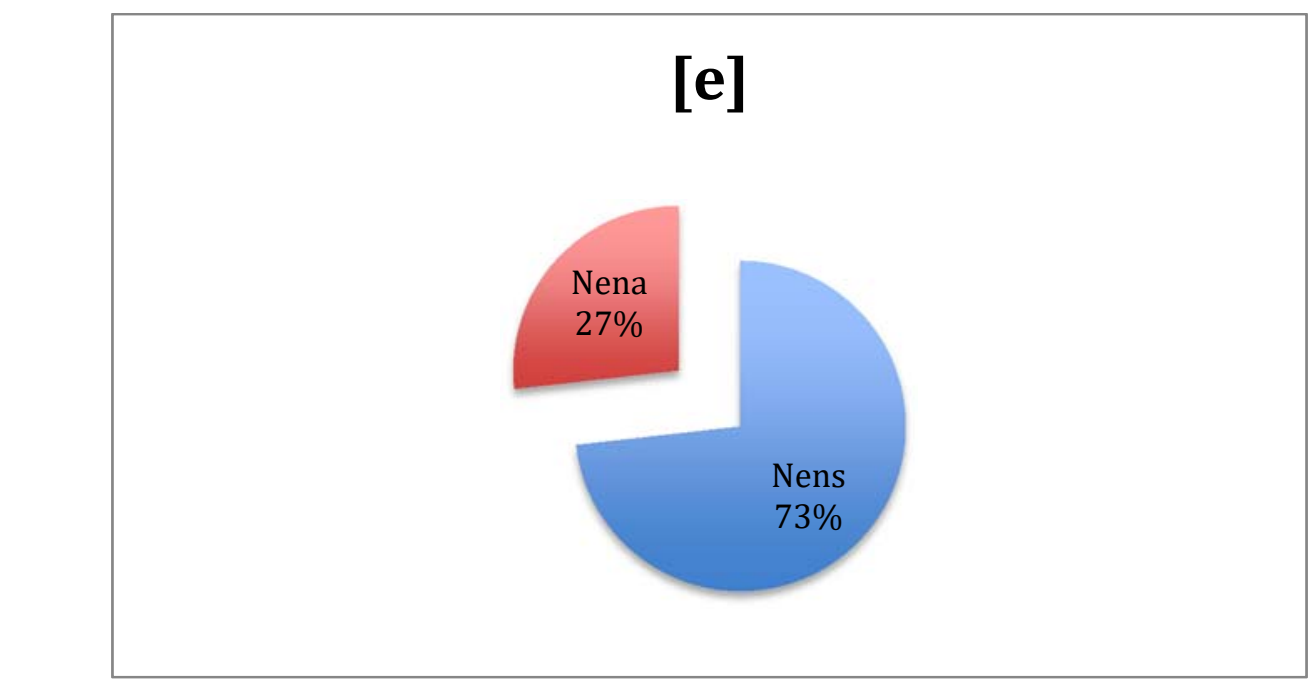

Gràfic 5. Percentatge de la vocal mitjana anterior alta produïda per dos nens i una nena. 
Les mitjanes dels valors acústics dels dos primers formants del so vocàlic [e] són les que podem veure a continuació:

\begin{tabular}{|l|c|c|}
\hline \multicolumn{1}{|c|}{ Informants } & {$[\mathbf{e}]$} & {$[\mathbf{e}]$} \\
\hline & $\mathbf{F}_{\mathbf{1}}$ & $\mathbf{F}_{\mathbf{2}}$ \\
\hline 2 nens & 487,62 & 1927,97 \\
\hline 1 nena & 484,53 & 1901,67 \\
\hline
\end{tabular}

Taula 6. Dades acústiques d'F1 i F2 de la vocal [e] del català produïda per nens nadius de la llengua Twi

\begin{tabular}{|c|c|c|c|}
\hline Informants & Corpus & [e] & [e] \\
\hline & & $F_{1}$ & $F_{2}$ \\
\hline 69 homes & PE & 464 & 1809 \\
\hline 62 dones & PE & 529 & 1969 \\
\hline
\end{tabular}

Taula 7. Resultats de les dades acústiques de l'F1 i F2 de la vocal [e] del català central obtinguts per Rius-Escudé (2015)

Si comparem els nostres resultats amb els resultats obtinguts per Rius-Escudé (2015) en què va analitzar les vocals del català central (vegeu taula 7) veiem que la diferència entre uns informants $\mathrm{i}$ els altres no és significativa quant a la producció de la vocal mitjana anterior alta.

Pel que fa al nostre estudi en l'F1 hem obtingut en els nens un 487,62 i un 484,53 en la nena, amb una diferència del $0,6 \%$. Si ho comparem amb els resultats analitzats per RiusEscudé (2015) els homes tenen un valor de 464 i les dones de 529, amb una diferència del $4,5 \%$.

Ara bé, si ens fixem ens els resultats obtinguts en els informants masculins en els dos estudis, el resultat de l' $F_{1}$ dels informants masculins en el nostre estudi és 487,62 i el de Rius-Escudé (2015) 461, amb una diferència del 4,9\%. Pel que fa als informants femenins, el resultat de l' $F_{1}$ del nostre estudi és 484,53 i el de Rius-Escudé (2015) és 529, amb una diferència del 9,1\%.

Els resultats de l'F2 del nostre estudi tenim un valor de 1927,97 en els nens i 1901,67 en la nena, aquests resultats són una diferència del 1,3\%. I en l'estudi de Rius-Escudé (2015) els homes han obtingut 1809 i les dones 1969, amb una diferència del 5,1\%.

Si comparem 1'F $F_{2}$ dels informants masculins del nostre estudi amb els de Rius-Escudé (2015), veiem que el valor de l'F2 en el nostre estudi és 1927,97 i el de Rius-Escudé 
(2015) 1809, amb una diferència del 6,2\%. Pel que fa als informants femenins, el resultat de 1 'F 2 del nostre estudi és 1901,67 i el de Rius-Escudé (2015) és 1969, amb una diferència del $3,5 \%$.

Així doncs, la diferència més rellevant la trobem en el primer formant $\left(\mathrm{F}_{1}\right)$ de la vocal [e] produïda pel sexe femení . Pel que fa al sexe masculí, trobem una mínima diferència a $l^{\prime} \mathrm{F}_{2}$.

Per tal de representar el valor acústic mitja de l' $F_{1}$ i de l' $F_{2}$ de la vocal mitjana anterior alta del català produïda per nens nadius de Twi de la forma més representativa possible, hem optat per un gràfic de dispersió ja que d'aquesta manera podem apreciar les realitzacions d'aquest so vocàlic de forma més acurada. Els valors de l' $F_{1}$ es troben a l'eix d'ordenades i els valors de l' $F_{2}$ a l'eix de les abscisses. A continuació podem veure dos gràfics de dispersió, un amb el camp de dispersió de la vocal mitjana anterior alta produïda pel sexe masculí i un amb el camp de dispersió de la vocal mitjana anterior alta produïda pel sexe femení.

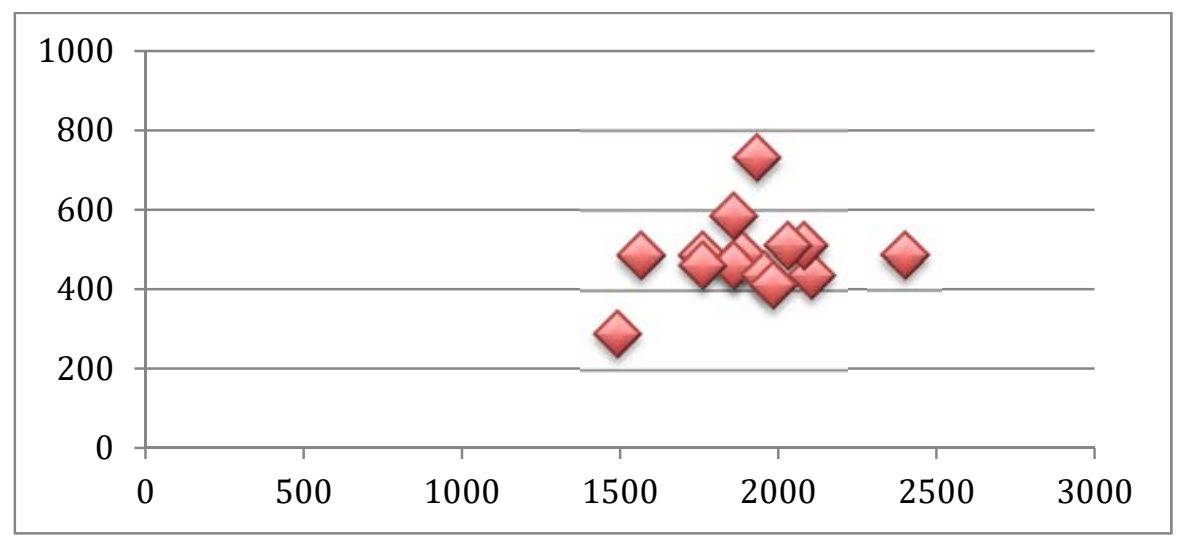

Gràfic 6. Camp de dispersió de la vocal [e] del català produïda per l'informant femení en parla espontània.

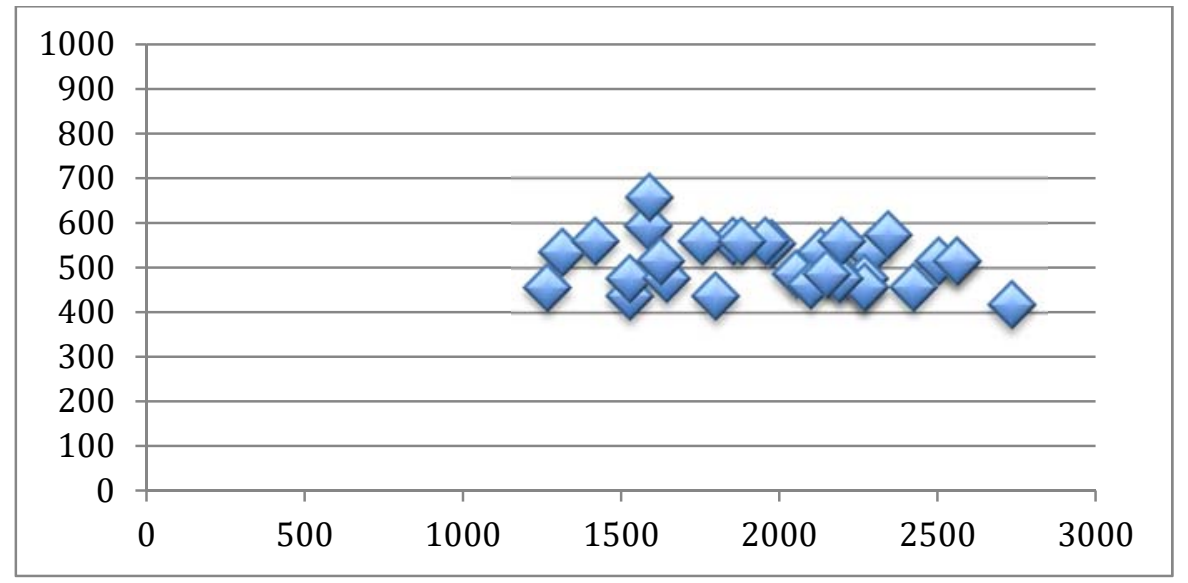

Gràfic 7. Camp de dispersió de la vocal [e] del català prodü̈da pels informants masculins en parla espontània. 
Si comparem els dos gràfics, podem veure que el camp de dispersió de la vocal mitjana anterior alta és molt més ampli en els nens que en la nena quant a l'F $F_{2}$, però molt més ampli quant a l' $F_{1}$ en les nenes. En la nena veiem que alguns valors arriben fins als 800 mentre que en els nens no passen dels 700 . Les produccions masculines es troben a una zona més inferior del gràfic que les produccions de la nena, és a dir, els valors d'ambdós formants de les vocals produïdes pels nens son més baixes. Seguint Rius-Escudé (2015) això significa que pronuncien la vocal amb menys avançament lingual, tal i com passa amb la producció de les vocal mitjana anterior alta dels seus informants masculins.

\subsection{Vocal posterior mitjana baixa [0]}

Seguint l'esquema de les vocals cardinals de l'AFI (Jones, 1917), el punt que la vocal posterior mitjana baixa ocupa en el triangle vocàlic es troba a la part dreta, al mig (veure figura 4) i la seva representació al sonograma és la que correspon (veure figura 7)

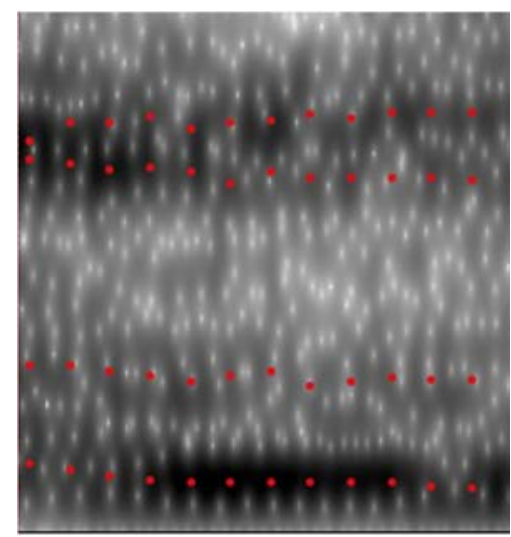

Figura 7. Sonograma de la vocal posterior mitjana baixa de coses

Com podem veure l'F1 i l'F2 de la [0] estan separats entre ells. Entre altres paraules que presenten aquest so trobem coses, bon, escola, hola, bona, però, roba.

Per fer l'anàlisi ens hem basat en un total de 38 vocals mitjanes posteriors baixes. Això representa el $25 \%$ del total del corpus analitzat. Un $47 \%$ han estat produïdes per nenes i un $53 \%$ per nens (veure gràfic 8 ).

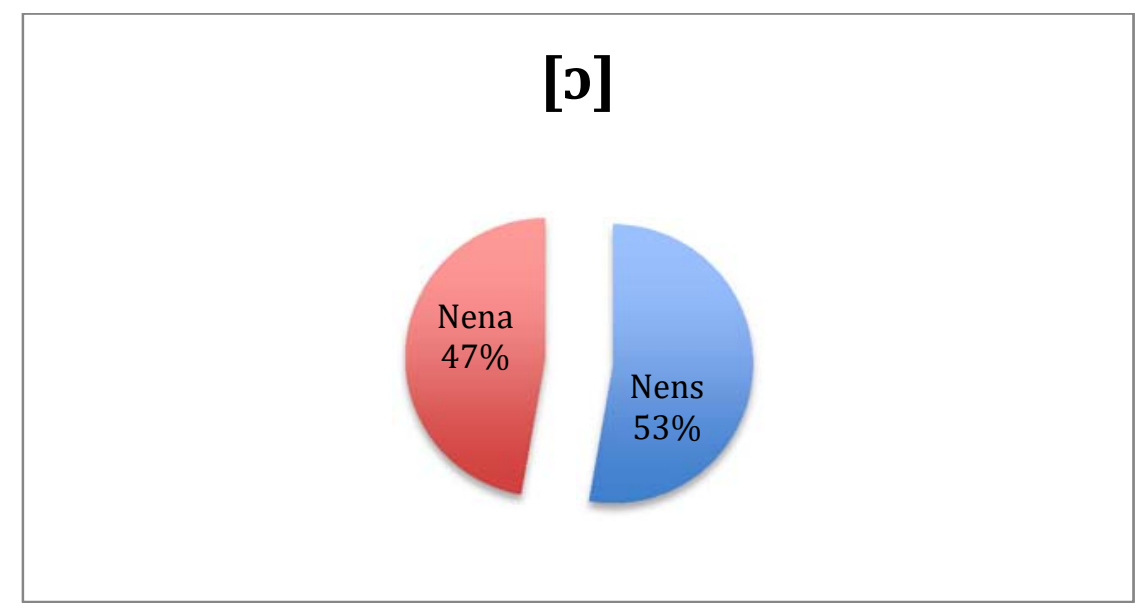

Gràfic 8 Percentatge de la vocal mitjana posterior baixa produïda per nens i nenes. 
Les mitjanes dels valors acústics dels dos primers formants del so vocàlic [0] són les que podem veure a continuació:

\begin{tabular}{|l|c|c|}
\hline \multicolumn{1}{|c|}{ Informants } & {$[\mathbf{0}]$} & {$[\mathbf{0}]$} \\
\hline & $\mathbf{F}_{\mathbf{1}}$ & $\mathbf{F}_{\mathbf{2}}$ \\
\hline 2 nens & 486,58 & 1275,83 \\
\hline 1 nena & 614,61 & 1258,68 \\
\hline
\end{tabular}

Taula 8. Dades acústiques d'F1 i F2 de la vocal [o] del català produïda per nens nadius de la llengua Twi

\begin{tabular}{|c|c|c|c|}
\hline Informants & Corpus & [O] & [O] \\
\hline & & $\mathbf{F}_{1}$ & $\mathbf{F}_{2}$ \\
\hline 97 homes & PE & 567 & 1168 \\
\hline 76 dones & PE & 675 & 1322 \\
\hline
\end{tabular}

Taula 9. Resultats de les dades acústiques de l'F1 i F2 de la vocal [o] del català central obtinguts per Rius-Escudé (2015)

Si comparem els nostres resultats amb els resultats obtinguts per Rius-Escudé (2015), en què va analitzar les vocals del català central (vegeu taula 9), veiem que la diferència entre uns informants i els altres no és significativa quant a la producció de la vocal mitjana posterior baixa.

Pel que fa al nostre estudi, en l' $F_{1}$ hem obtingut en els nens un 486,58 i un 614,61 en la nena, amb una diferència del $8,6 \%$. Si ho comparem amb els resultats analitzats per RiusEscudé (2015), els homes obtenen un valor de 567 i les dones de 614,61, amb una diferència del $8,5 \%$. El resultat de 1 ' $F_{1}$ dels informants masculins del nostre estudi és 486,58 i el de Rius-Escudé (2015) 567, amb una diferència del 16,4\%. Pel que fa als informants femenins, el resultat de l' $F_{1}$ del nostre estudi és 614,61 i el de Rius-Escudé (2015) és 675, amb una diferència de 9,8\%.

En els resultats de l' $F_{2}$ del nostre estudi tenim un valor de 1275,83 en els nens i 1258,68 en la nena, aquests resultats són una diferència del 1,4\%. I en l'estudi de Rius-Escudé (2015) els homes han obtingut 1168 i les dones 1322, amb una diferència del 13,2\%.

El resultat de l' $F_{2}$ dels informants masculins del nostre estudi és 1275,83 i el de RiusEscudé (2015) 1168, amb una diferència del 8,5\%. Pel que fa als informants femenins, el resultat de l'F $F_{2}$ del nostre estudi és 1258,68 i el de Rius-Escudé (2015) és 1322, amb una diferència del $5 \%$. 
Si analitzem els resultats podem comprovar que en general no hi ha una gran diferència, tot i que podríem remarcar l'F $F_{1}$ masculí a diferència del femení.

Per tal de representar el valor acústic mitjà de $l^{\prime} F_{1}$ i de l'F $F_{2}$ de la vocal mitjana posterior baixa del català produïda per nens nadius de Twi de la forma més representativa possible, hem optat per un gràfic de dispersió ja que d'aquesta manera podem apreciar les realitzacions d'aquest so vocàlic de forma més acurada. Els valors de l' $F_{1}$ es troben a l'eix d'ordenades i els valors de l'F 2 a l'eix de les abscisses. A continuació podem veure dos gràfics de dispersió, un amb el camp de dispersió de la vocal mitjana posterior baixa produïda pel sexe masculí i un amb el camp de dispersió de la vocal mitjana posterior baixa produïda pel sexe femení.

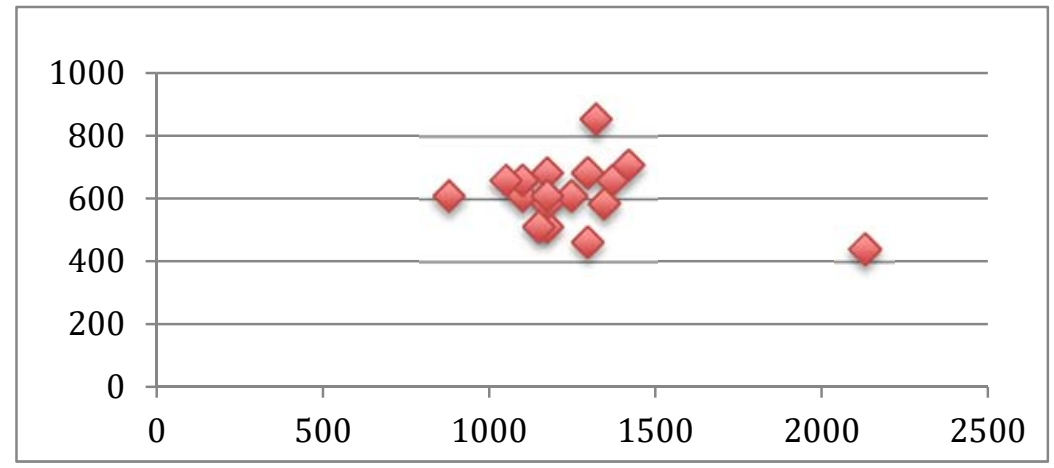

Gràfic 9. Camp de dispersió de la vocal [o] del català produïda per l'informant femení en parla espontània.

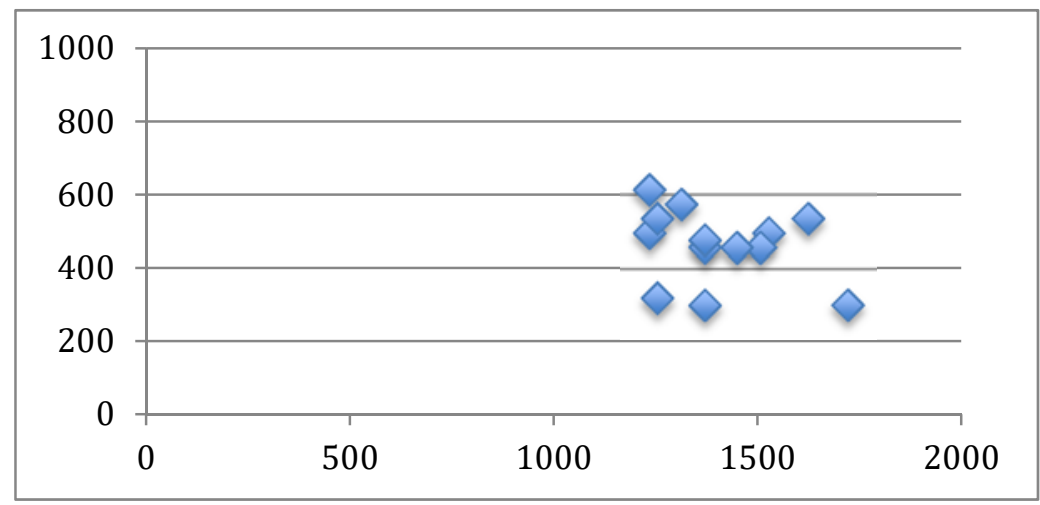

Gràfic 10. Camp de dispersió de la vocal [o] del català produïda pels informants masculins en parla espontània.

Si comparem els dos gràfics, podem veure que el camp de dispersió de la vocal mitjana posterior baixa és molt més ampli en la nena que en els nens quant a l' $F_{2}$, però molt més ampli quant a l' $F_{1}$ en les nenes. En la nena veiem que alguns valors que passen dels 800 mentre que en els nens no arriben als 700 . Les produccions masculines es troben a una zona més inferior del gràfic que les produccions de la nena, és a dir, els valors d'ambdós formants de les vocals produïdes pels nens son més baixes. Seguint Rius-Escudé (2015) això significa que les dones pronuncien la vocal més oberta. 


\subsection{Vocal posterior mitjana alta $[0]$}

Seguint l'esquema de les vocals cardinals de l'AFI (Jones, 1917), la vocal mitjana posterior alta ocupa la part dreta en el triangle vocàlic, entre la $[\mathrm{u}]$ i la $[\mathrm{o}]$ (veure figura $8)$.

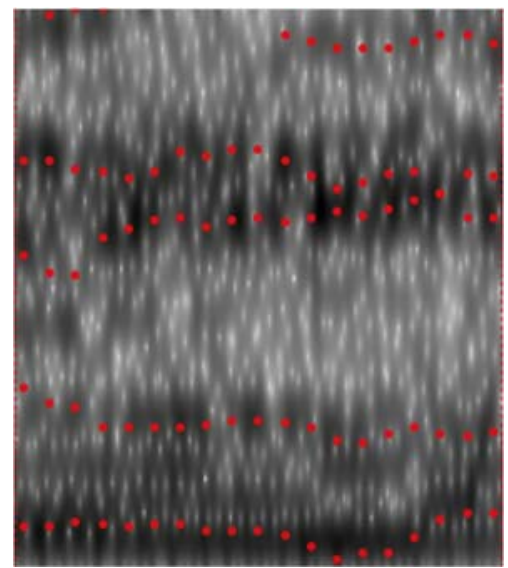

Figura 8. Sonograma de la vocal mitjana posterior alta d'avió

Com podem veure l' $F_{1}$ i l' $F_{2}$ de la [o] estan separats. Entre altres paraules que presenten aquest so trobem avió, moltes, persones, por.

Per fer l'anàlisi ens hem basat en un total de 32 vocals mitjanes posteriors altes. Això representa el 22\% del total del corpus analitzat. Un 34\% han estat produïdes per nenes i un $66 \%$ per nens (veure gràfic 11 ).

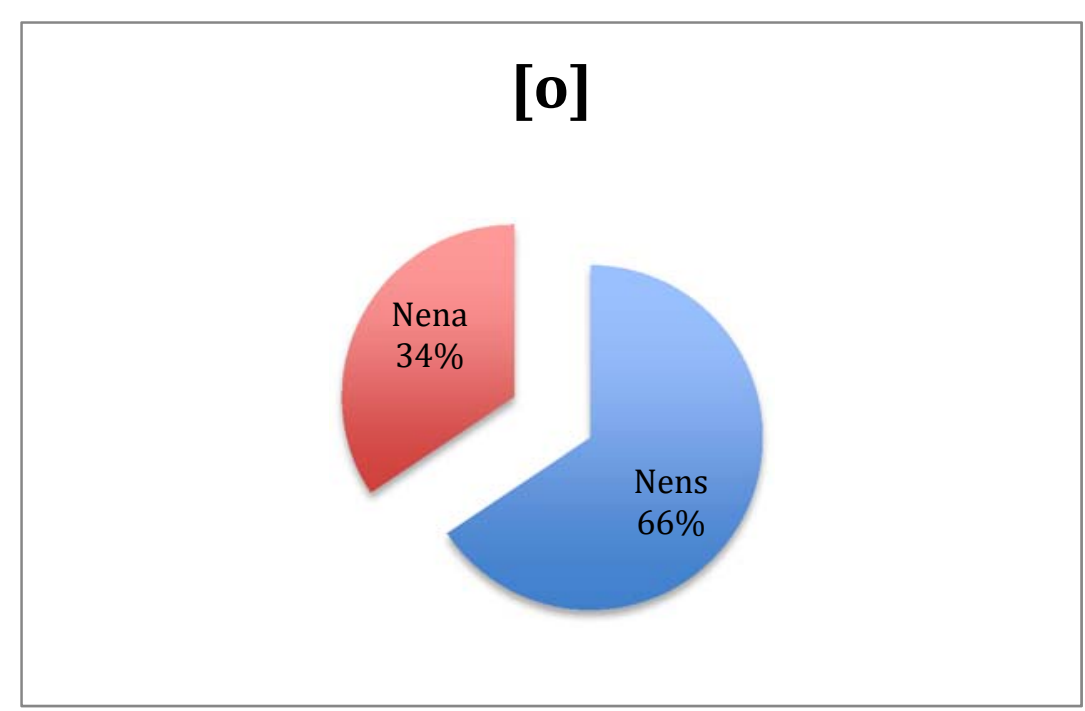

Gràfic 11. Percentatge de la vocal mitjana posterior alta produïda per dos nens $i$ una nena.

Les mitjanes dels valors acústics dels dos primers formants del so vocàlic [e] són les que podem veure a continuació: 


\begin{tabular}{|l|c|c|}
\hline Informants & [0] & [0] \\
\hline & $\mathbf{F}_{\mathbf{1}}$ & $\mathbf{F}_{\mathbf{2}}$ \\
\hline 2 nens & 491,05 & 1277,43 \\
\hline 1 nena & 498,94 & 1216,00 \\
\hline
\end{tabular}

Taula 10. Dades acústiques d'F1 i F2 de la vocal [o] del català produïda per nens nadius de la llengua Twi

\begin{tabular}{|c|c|c|c|}
\hline Informants & Corpus & [0] & [0] \\
\hline & & $F_{1}$ & $F_{2}$ \\
\hline 97 homes & PE & 518 & 1219 \\
\hline 76 dones & PE & 597 & 1314 \\
\hline
\end{tabular}

Taula 11. Resultats de les dades acústiques de l'F1 i F2 de la vocal [o] del català central obtinguts per Rius-Escudé (2015)

Si comparem els nostres resultats amb els resultats obtinguts per Rius-Escudé (2015), en què va analitzar les vocals del català central (vegeu taula 11), veiem que la diferència entre uns informants i els altres no és significativa quant a la producció de la vocal mitjana posterior alta.

Pel que fa al nostre estudi en l'F1 hem obtingut en els nens un 491,05 i un 498,94 en la nena, amb una diferència del $1,6 \%$. Si ho comparem amb els resultats analitzats per RiusEscudé (2015) els homes tenen un valor de 518 i les dones de 597, amb una diferència del 15,3\%. Comparant els resultats dels informants masculins del nostre estudi amb els de Rius-Escudé (2015) ens adonem que el resultat de l' $F_{1}$ dels informants masculins del nostre estudi és 491,05 i el de Rius-Escudé (2015) 518, amb una diferència del 5,5\%. Pel que fa als informants femenins, el resultat de l' $F_{1}$ del nostre estudi és 498,94 i el de RiusEscudé (2015) és 597, amb una diferència del 19,65.

Els resultats de l'F2 del nostre estudi tenim un valor de 1277,43 en els nens i 1216 en la nena, aquests resultats són una diferència del 4,8\%. I en l'estudi de Rius-Escudé (2015) els homes han obtingut $1219 \mathrm{i}$ les dones 1314, amb una diferència del 7,8\%.

Si comparem l'F $F_{2}$ dels informants masculins del nostre estudi amb el de Rius-Escudé (2015), veiem que el resultat dels informants masculins del nostre estudi és 1277,43 i el de Rius-Escudé (2015) 1219, amb una diferència del 4,5\%. Pel que fa als informants femenins, el resultat de l'F2 del nostre estudi és 1216,00 i el de Rius-Escudé (2015) és 1314 , amb una diferència del $8,1 \%$.

Si analitzem els resultats podem observar que el valor més significatiu és a l'F $F_{1}$ del sexe femení. Pel que fa al sexe masculí el valor és insignificant. 
Per tal de representar el valor acústic mitja de l' $F_{1}$ i de l'F $F_{2}$ de la vocal mitjana posterior alta del català produïda per nens nadius de Twi de la forma més representativa possible, hem optat per un gràfic de dispersió ja que d'aquesta manera podem apreciar les realitzacions d'aquest so vocàlic de forma més acurada. Els valors de l' $F_{1}$ es troben a l'eix d'ordenades i els valors de l' $F_{2}$ a l'eix de les abscisses. A continuació podem veure dos gràfics de dispersió, un amb el camp de dispersió de la vocal mitjana posterior alta produïda pel sexe masculí i un amb el camp de dispersió de la vocal mitjana posterior alta produïda pel sexe femení.

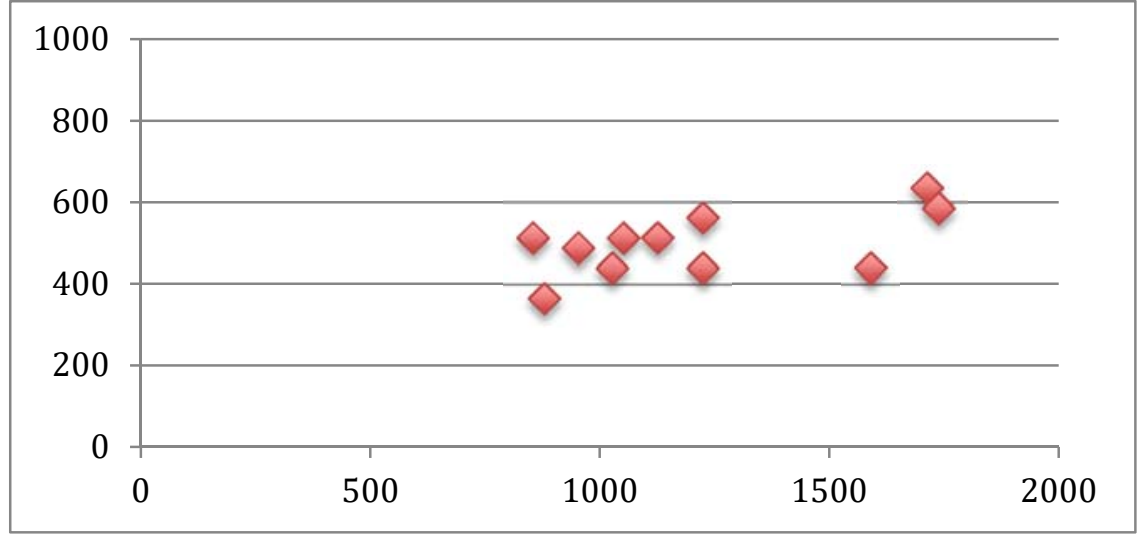

Gràfic 12. Camp de dispersió de la vocal [o] del català produïda per l'informant femeni en parla espontània.

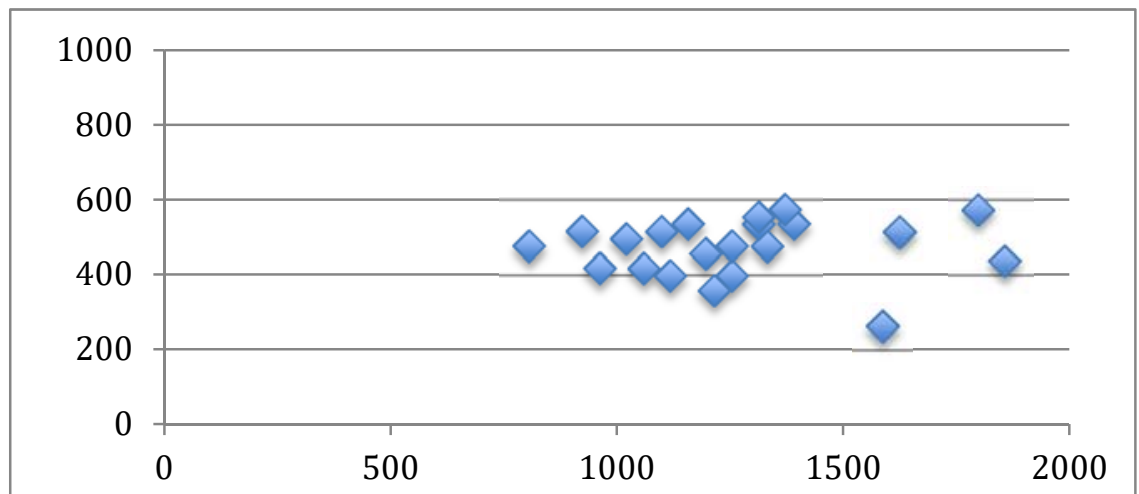

Gràfic 13. Camp de dispersió de la vocal [o] del català produïda pels informants masculins en parla espontània.

Si comparem els dos gràfics, podem veure que el camp de dispersió de la vocal mitjana posterior alta és molt semblant en els nens i en la nena pel que fa a l' $F_{1}$ i l' $F_{2}$. En la nena $i$ els nens veiem que alguns valors arriben fins als 600. Les produccions masculines $i$ femenines es troben a una zona més central del gràfic. També podem observar que tant en el gràfic dels nens com en la nena hi ha realitzacions molt allunyades entre si. El camps de dispersió de la vocal mitjana posterior alta és molt ampli i dispers, tant en els nens com en les nenes. 


\section{DISCUSSIÓ DELS RESULTATS}

Per tal de començar la discussió dels resultats i en base a que no hi ha un estudi previ en el qual s'analitza la parla espontània del català produïdes per informants de parla Twi vam marcar una sèrie d'objectius inicials:

1. Descriure acústicament les vocals mitjanes en parla espontània en llengua catalana produïdes per informants que tenen el Twi com a llengua materna.

2. Comparar i valorar els resultats obtinguts amb l'estudi de Rius-Escudé (2015) en què es descriuen les vocals del català central en parla espontània. Observant els fenòmens de transferència fonètica observats entre el Twi i la llengua catalana.

Un cop analitzats els sons $[\varepsilon],[\mathrm{e}],[\mathrm{o}] \mathrm{i}[\mathrm{o}]$, dels nens catalanoparlants d'origen ghanès per intentar veure si la llengua catalana en aquests entorns plurilingües rep influències de les llengües maternes, que modifiquen o afecten el desenvolupament de les capacitats orals en llengua catalana, hem obtingut els següents resultats:

\begin{tabular}{|c|c|c|c|c|c|c|c|c|}
\hline INFORMANTS & \multicolumn{2}{|c|}{$[\varepsilon]$} & \multicolumn{2}{c|}{ [e] } & \multicolumn{2}{c|}{ [0] } & \multicolumn{2}{c|}{ [0] } \\
\hline & $F_{1}$ & $F_{2}$ & $F_{1}$ & $F_{2}$ & $F_{1}$ & $F_{2}$ & $F_{1}$ & $F_{2}$ \\
\hline NENS & 552,53 & 1972,92 & 487,62 & 1927,97 & 486,58 & 1275,83 & 491,05 & 1277,43 \\
\hline NENA & 645,26 & 1904,81 & 484,53 & 1901,67 & 614,61 & 1258,68 & 498,94 & 1216 \\
\hline
\end{tabular}

Taula 12. Valors acústics mitjans dels dos primers formants de les vocals [E], [e], [o] $i$ [o] produïdes per nens nadius de la llengua Twi.

\begin{tabular}{|c|c|c|c|c|c|c|c|c|}
\hline Informants & [i] & [e] & {$[\varepsilon]$} & [ə] & [i] & [e] & [ع] & [ə] \\
\hline & $F_{1}$ & $F_{1}$ & $F_{1}$ & $F_{1}$ & $F_{2}$ & $F_{2}$ & $F_{2}$ & $F_{2}$ \\
\hline homes & 379 & 462 & 556 & 565 & 2004 & 1823 & 1740 & 1442 \\
\hline \multirow[t]{3}{*}{ dones } & 440 & 527 & 631 & 670 & 2115 & 2014 & 1968 & 1596 \\
\hline & [u] & [0] & [ग] & [a] & [u] & [o] & [ग] & [a] \\
\hline & $F_{1}$ & $F_{1}$ & $F_{1}$ & $F_{1}$ & $F_{2}$ & $F_{2}$ & $F_{2}$ & $F_{2}$ \\
\hline homes & 366 & 518 & 567 & 656 & 739 & 1219 & 1168 & 1435 \\
\hline dones & 376 & 597 & 675 & 794 & 687 & 1314 & 1322 & 1516 \\
\hline
\end{tabular}

Taula 13. Resultats de les dades acústiques de l'F1 i F2 de les vocals del català central en parla espontània de les obtinguts per Rius-Escudé (2015).

\begin{tabular}{|l|c|c|c|c|}
\hline INFORMANTS & {$[\varepsilon]$} & {$[\mathrm{e}]$} & {$[\mathrm{o}]$} & {$[0]$} \\
\hline
\end{tabular}




\begin{tabular}{|l|l|l|l|l|l|l|l|l|}
\hline & $\mathrm{F}_{1}$ & $\mathrm{~F}_{2}$ & $\mathrm{~F}_{1}$ & $\mathrm{~F}_{2}$ & $\mathrm{~F}_{1}$ & $\mathrm{~F}_{2}$ & $\mathrm{~F}_{1}$ & $\mathrm{~F}_{2}$ \\
\hline NEN & 552,5 & 1972,97 & 487,62 & 1927,97 & 486,58 & 1275,83 & 491,05 & 1277,43 \\
\hline HOME & 556 & 1752 & 464 & 1809 & 567 & 1168 & 518 & 1219 \\
\hline$\%$ & $0,7 \%$ & $11,2 \%$ & $4,9 \%$ & $6,2 \%$ & $14,4 \%$ & $8,5 \%$ & $5,5 \%$ & $4,5 \%$ \\
\hline NENA & 645,26 & 1904,81 & 484,53 & 1901,67 & 614,61 & 1258,68 & 498,94 & 1216 \\
\hline DONA & 632 & 1969 & 529 & 1969 & 675 & 1322 & 597 & 1314 \\
\hline$\%$ & $2 \%$ & $3,3 \%$ & 9,1 & $3,5 \%$ & $9,8 \%$ & $5 \%$ & $19,6 \%$ & $8,1 \%$ \\
\hline
\end{tabular}

Taula 14. Comparació dels resultats obtinguts en l'estudi amb els resultats obtinguts per Rius-Escudé (2015)

Pel que fa als valors d'F $F_{1}$ de les vocals en homes, els nostres resultats són inferiors a les vocals $[\varepsilon],[\circ]$ i [o] en comparació amb l'estudi de Rius-Escudé (en el qual ens hem basat degut a la seva tipologia: és l'únic estudi on s'aporten dades basades en parla espontània) excepte els de la [e] que són superiors. Així doncs, podem pensar que en els parlants de Twi en parla espontània del català la vocal [e] és més oberta. Hem de tenir en compte, però que els sons analitzats en el nostre estudi han estat produïts per nens i una nena, mentre que a l'estudi de Rius-Escudé (2015) els sons van estar produïts per homes i dones. Així doncs, estem comparant nens amb homes adults i una nena amb dones adultes.

En l'F $F_{2}$ de les vocals analitzades, els valors són més alts en el nostre estudi que en el de Rius-Escudé (2015).

Els valors d' $F_{1}$ de les vocals produïdes per informants femenins en el nostre estudi són inferiors a les vocals [e], [o] i [o], els de la [ع] que són superiors. Així doncs, el sexe femení pronuncia la $[\varepsilon]$ amb més obertura que els informants del català central.

En l'F2, en canvi, els valors són inferiors, en comparació amb l'estudi de Rius-Escudé (2015), en totes les vocals analitzades.

Si ens fixem en els resultats dels sons vocàlics analitzats $[\varepsilon],[\mathrm{e}],[0] \mathrm{i}[\mathrm{o}]$ i els comparem amb Rius-Escudé (2015) podem dir que la diferència més gran la trobem en el primer formant de la [o] dels informants femenins, en el qual la diferència entre la nena analitzada en el nostre estudi i les dones analitzades a Rius-Escudé (2015) és del 19,65\%.

Un dels nostres objectius era analitzar si s'observaven fenòmens de transferència fonètica entre el Twi i la llengua catalana. Després d'analitzar els resultats obtinguts, destaquem que, en general, no trobem diferències significatives entre les vocals produïdes pels informants del català central i pels informants catalanoparlants la L1 dels quals és el Twi. Si considerem els diferents valors de cada so i els representem en un gràfic de dispersió, es poden veure les zones de confluència $\mathrm{i}$ les pròpies de cadascun. 


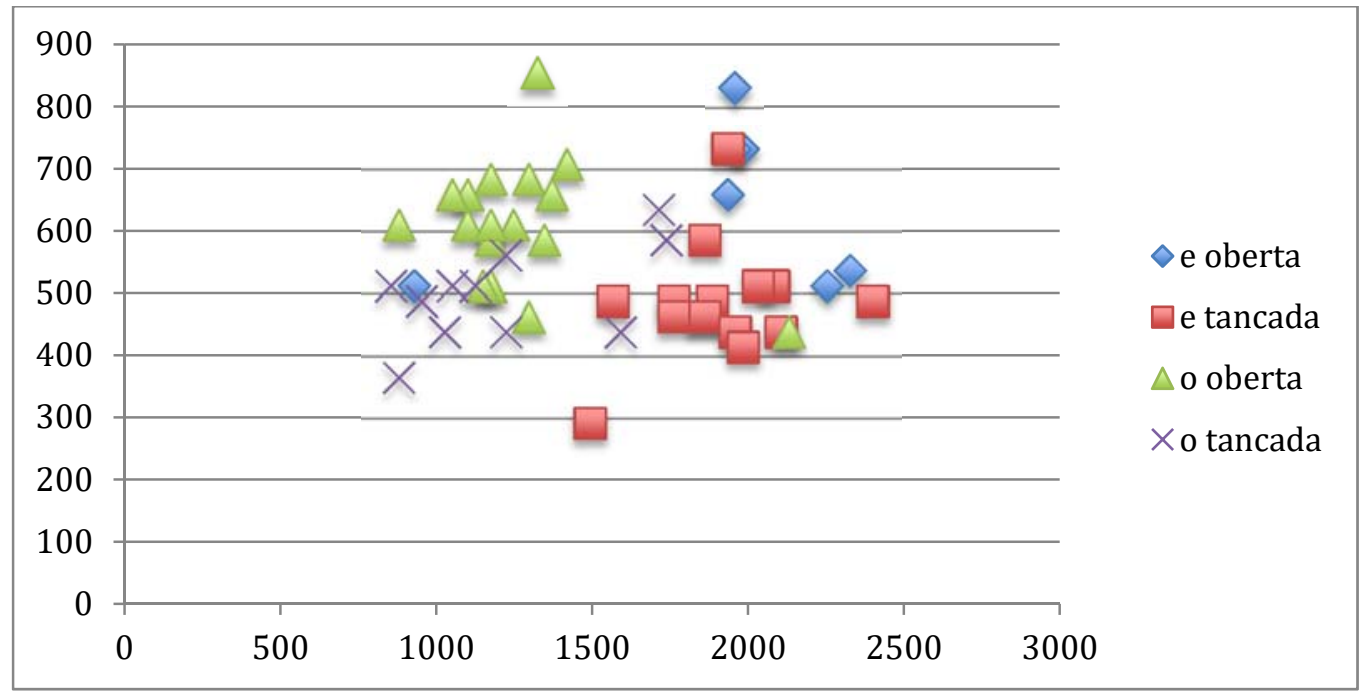

Gràfic 14. Dispersió de les vocals del català [E], [e], [o] i [o], produïda per l'informant femeni en parla espontània.

Al gràfic 14, observem que tot i que cada vocal té una zona pròpia, també hi ha una zona de confluència important entre elles.

A continuació, presentem el camp de dispersió de l'informant femenina, en aquest cas i si ho comparem amb els informants masculins, també és molt dispers, però amb una tendència més àmplia. En similitud amb el dels nens podem observar que els sons ocupen espais similars en la part central-superior del gràfic.

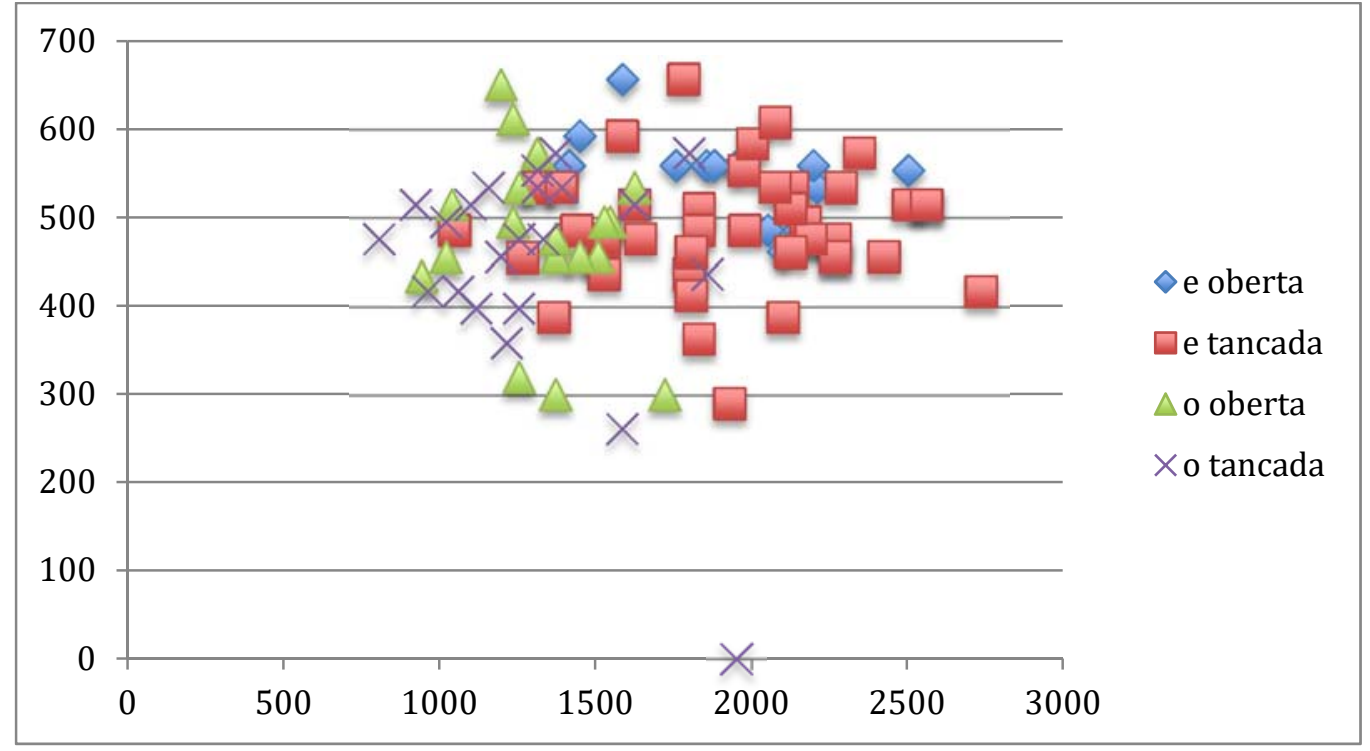

Gràfic 15. Dispersió de les vocals del català [E], [e], [o] i [o], produïda pels informants masculins en parla espontània.

$\mathrm{Al}$ gràfic 15, observem que tant les vocals anteriors com les posteriors dels sons $[\varepsilon],[\mathrm{e}]$, [0] i [o] presenten un camp de dispersió força ampli, tot i que queda molt concentrat a la part central, superior. Segons Rius-Escudé (2015), això explica la dificultat de produir les vocals mitjanes $[\varepsilon],[\mathrm{e}],[0]$ i $[\mathrm{o}]$. 
Tenint en compte tots els resultats anteriors analitzats, podem concloure que tot i que en un inici pensàvem que les vocals mitjanes dels parlants Twi en la parla espontània del català rebien influència de la seva llengua materna, al final podem veure que no és així. Com a conseqüència, un estudi de futur podria ser analitzar la vocal anterior alta [i], la vocal posterior baixa [a], la posterior alta $[\mathrm{u}]$ i la vocal mitjana alta central [э] per veure si hi ha interferència fonètica en aquests sons o al igual que passa amb les vocals mitjanes $[\varepsilon],[\mathrm{e}],[0] \mathrm{i}[\mathrm{o}]$, no hi ha diferències rellevants.

\section{REFERÈNCIES BIBLIOGRÀFIQUES}

Bonet, A. R. (2012). Competències lectores i èxit escolar. Fundació Jaume Bofill.

Best, C. T. (1995). A direct realist view of cross-language speech perception. A W. Strange (Ed.), Speech perception and linguistic experience: issues in crosslanguage researchperience: Issues in cross-language research (pp. 171204). Baltimore, MD: York Press.

Best, C. T., \& Tyler, M. D. (2007). Nonnative and second-language speech perception: Commonalities and complementarities. A O.-S. Bohn \& M. J. Munro (Eds.), Language experience in second language speech learning: In honor of James Emil Flege (pp. 13-34). Amsterdam: John Benjamins.

Collet, J., \& Tort, A. (2012). Famílies, escola i èxit. Millorar els vincles per millorar els resultats, (35).

Davis, Jeffrey E. 1990. Linguistic transference and interference: Interpreting between English and ASL. A C. Lucas (Ed.), Sign Language Research: Theoretical Issues. Washington, DC: Gallaudet University Press.

Recasens, D. (1986). Estudis de fonètica experimental del català oriental central, Barcelona: Publicacions de l'Abadia de Montserrat.

Recasens, D. (1993). Fonètica i fonologia. Barcelona: Enciclopèdia Catalana.

Rius-Escudé, A. (2015). Les vocals del català central en parla espontània (tesi doctoral). Barcelona: Universitat de Barcelona.

Serra, J. M., Perera, S., Siqués Jofré, C., Mayans Balcells, P., \& Canal, I. (2008). Adaptació escolar, actituds $i$ aprenentatge del català en l'alumnat de les aules d'acollida de Primària i Secundària a Catalunya (Curs 2005-2006).

Thomason, S. (2001). Language contact: An introduction. Edinburgh: Edinburgh University Press. 